Volumen 17 Número 2, Abril - Junio 2022, pp. 1-25, e560

DOI: https://doi.org/10.21919/remef.v17i2.560

(Primera recepción: 10/octubre/2020, última recepción: 19/mayo/2021, aceptado: 16/junio/2021, publicado: $17 /$ noviembre/2021)

\title{
Los efectos del crédito bancario otorgado a la industria y al consumo en el crecimiento económico: evidencia de México, 1994-2017
}

\author{
David Salvador Cisneros Zepedaำ - Universidad Autónoma de Sinaloa, México
}

Este artículo analiza empíricamente la relación entre el crédito bancario otorgado a la industria y al consumo y el crecimiento económico en México, utilizando como método un análisis de regresión, para medir los efectos a largo plazo; además, se implementó una variable dicotómica, para observar la existencia de posibles cambios en la relación entre las variables con la ocurrencia de la crisis financiera del 2008. Se encontró que, a pesar de ser un país con un sistema financiero poco eficiente, existe una relación positiva con el crecimiento económico en el largo plazo; asimismo, la relación entre el PIB y el crédito bancario otorgado a la industria, denota un cambio tras la crisis financiera del 2008, donde el segundo dejó de tener efectos positivos sobre el crecimiento económico. Los obstáculos del estudio se deben a que las bases de datos sobre crédito bancario dejaron de actualizarse en INEGI. Sin duda, el papel de banca sobre el crecimiento aún es importante para México, y se debe pensar en mejores regulaciones sobre la implementación del crédito para la industria.

Clasificación JEL: E00, E44, E51, F41, F43, G20.

Palabras clave: Crédito Bancario, Industria, Crecimiento Económico, PIB, Consumo, Largo Plazo, Series de Tiempo.

\section{The Effects of Bank Loans Granted to Industry and Consumption on Economic Growth: Evidence from Mexico, 1994-2017}

This article empirically analyzes the relationship between bank credit granted to industry and consumption and economic growth in Mexico, using regression analysis as a method to measure longterm effects; Furthermore, a dichotomous variable was implemented to observe the existence of possible changes in the relationship between the variables with the occurrence of the 2008 financial crisis. It was found that, despite being a country with an inefficient financial system, there is a positive relationship with long-term economic growth; Likewise, the relationship between GDP and bank credit granted to industry denotes a change after the financial crisis of 2008 , where the latter stopped having positive effects on economic growth. The obstacles to the study are due to the fact that the databases on bank credit were no longer updated in INEGI. Undoubtedly, the role of banking on growth is still important for Mexico, and better regulations on the implementation of credit for the industry should be considered.

JEL Classification: E00, E44, E51, F41, F43, G20.

Keywords: Bank Loans, Industry, Economic Growth, GDP, Consumption, Long-Term.

${ }^{1}$ Autor de correspondencia. Departamento de Ingeniería de Sistemas, Facultad de Ciencias, UNAM Av. Universidad № 3000, Universidad Nacional Autónoma de México, C.U., Ciudad de México, C.P. 04510, teléfono: 55-25223398, e-mail: jaimberto@hotmail.com

* Sin fuente de financiamiento para el desarrollo de la investigación 


\section{Introducción}

Este documento analiza empíricamente si los créditos bancarios - tanto los concedidos por la Banca Comercial como por la Banca de Desarrollo - otorgados a la industria y al consumo, están fuertemente correlacionados con los cambios en el crecimiento económico; observar si existe un cambio en el comportamiento del crédito bancario respecto al crecimiento económico, antes y después de una crisis financiera mundial. Esto usando datos sobre la economía mexicana en un periodo de 24 años - de 1994 al 2017, lapso que contempla la crisis financiera mundial del 2008 -. Esta investigación proporciona evidencia empírica sobre los debates teóricos respecto al vínculo entre el sector bancario, con el crédito otorgado a los sectores ya mencionados, y el crecimiento económico a largo plazo.

De esta manera, se utiliza un modelo de regresión de series de tiempo, trabajando con datos sobre montos de créditos otorgados por las instituciones bancarias al sector industrial y al consumo, todo respecto al Producto Interno Bruto. No obstante, cabe recalcar que antes se empleaba el método de investigación cross-country, no obstante, Levine (1998) cambia esa metodología por una regresión de series de tiempo, debido a la diferencia existente entre un país y otro, aceptando las series de tiempo como una herramienta más factible para estudiar los efectos a largo plazo en materia macroeconómica; de igual forma, Arestis, Demetriades y Luintel (2001) utilizan una regresión de series de tiempo para analizar el desarrollo financiero y sus efectos en el crecimiento económico a largo plazo.

En ese sentido, se pueden incluir las siguientes interrogantes: ¿Qué tipo de relación existe entre el crédito bancario, otorgado al sector industrial y al consumo, y el crecimiento económico a largo plazo en un país en vías de desarrollo? ¿Cuáles son los efectos del crédito bancario otorgado al sector industrial y al consumo sobre el crecimiento económico a largo plazo en un país en vías de desarrollo? ¿Cómo se comportan los efectos del crédito bancario, otorgados al sector industrial y al consmo, sobre el crecimiento económico a largo plazo? Para responder estas preguntas partimos del modelo de regresión utilizada por Levine (1998), agregándole las importaciones de bienes capital y las exportaciones, como variable control, para examinar los efectos a largo plazo del crédito sobre el crecimiento económico. Esto con el argumento de la función del crédito bancario como detonante de la mejora de los sectores productivos, impactando en los niveles del crecimiento económico.

El documento cuenta con 3 secciones más; en la primera, se aborda la literatura sobre la cual se han abordado temas similares al de este artículo, con la intención de dar sustento teórico, también, el contexto del comportamiento de las variables entre 1994 y 2017 (la serie no logró ser más actual, ya que los datos de crédito bancario del BIE del INEGI no se actualizarón y fueron eliminados; mientras los datos de Banxico y la CNBV, no empatan con las series del organismo antes mencionado); en la segunda, se hace alusión a las variables analizadas y sus descripciones, la predicción de las variables independientes con las variables explicadas, el desarrollo de las regresiones de los modelos de series de tiempo propuestos y el análisis de los resultados empíricos; y por último, la tercera sección contiene las conclusiones y discusiones. 


\section{Revisión de literatura}

La relación del sistema financiero - ya sea mercado de valores o crédito bancario - con el crecimiento económico empieza con Bagehot (1873), Schumpeter (1912), McKinnon (1973) y Shaw (1973), argumentando la importancia del sector bancario en el crecimiento, y cómo éste puede incentivarlo a través de inversiones productivas - como la innovación -. Por otra parte, existen estudios sobre el papel financiero de una vertiente más general y sus efectos en la economía, los cuales toman como variable explicativa al nivel de desarrollo financiero; Gurley y Shaw (1955) argumentan la existencia de una clara relación con el desarrollo financiero; es decir, un incremento del ingreso aumenta el deseo de crear otros activos dentro del sistema financiero, siempre y cuando haya unidades superavitarias que las puedan consumir (acumular).

Siguiendo la idea anterior, Landa (2019), Tóala, Navarro y Hablich (2018), Montoya (2016) y Hassan, Sánchez y Yu (2011), determinan la relación entre el crecimiento económico y el desarrollo financiero a través de la siguiente lógica: un sector financiero bien desarrollado puede contribuir significativamente en el crecimiento de las tasas de ahorro y la inversión, conduciendo al crecimiento económico. Es decir, aseveran la existencia de una relación positiva entre ambas, siempre que haya un buen funcionamiento del sistema financiero, pero depende de las políticas económicas y financieras. En esa misma línea, Támara, Eusse y Castellón (2017), Zhang, Wang y Wang (2012) y Huang y Lin (2009), investigan la relación entre el desarrollo financiero y el crecimiento económico, encontrando una asociación positiva entre ambas variables; los primeros, desde una perspectiva local, donde depende mucho del tamaño y condiciones de la ciudad; los segundos, toman en cuenta el ingreso de cada país.

En ese sentido, el desarrollo financiero se puede fraccionar en dos vertientes de impacto en el crecimiento económico: 1) desde el mercado de valores - también conocido como mercado bursátil -; y, 2) desde el quehacer de las instituciones bancarias - el crédito otorgado al sector bancario. Aunque el presente documento se enfoca en el papel de las instituciones bancarias, se toma en cuenta, para el presente apartado, las dos.

Para el caso del sector bancario, la idea de la captación de ahorro y su canalización hacia inversiones más productivas ha cambiado con la evolución de la discusión del crecimiento endógeno en la década de 1988 (Greenwood y Jovanovic, 1990; Bencivenga y Smith, 1991; King y Levine, 1993). King y Levine (1993), hablan sobre cómo el nivel de intermediación financiera es un buen predictor del crecimiento económico a largo plazo, el capital humano y el mejoramiento de la productividad.

A pesar de que el enfoque histórico ha sido sobre la banca, existe literatura donde se debate el vínculo con el desarrollo financiero y el mercado bursátil a largo plazo. Levine (1991) y Bencivenga et al. (1995) parten de modelos donde los mercados bursátiles son más líquidos que las instituciones bancarias. En otras palabras, ni los bancos ni los intermediarios financieros podían crear fondos prestables por si mismos; la única manera de crear fondos prestables es a través del ahorro en conjunto con el sistema financiero, o la venta de deuda a través de acciones en el mercado bursátil.

El papel de las instituciones bancarias, a través del crédito para el beneficio del crecimiento económico, tiene sus críticas en la operación de los intermediarios financieros. Lucas (1988), señalan que los bancos sobre estresan el crecimiento económico o responde pasivamente al mismo, argumentando que la relación entre éstos se da al revés, es decir, el crecimiento económico impulsa la demanda de servicios financieros; Smith (1994) y Obstfeld (1994) argumentan cómo la colocación 
de los créditos se vuelve ineficiente, generando un incremento del riesgo financiero; Greenwood y Hanson (2013), señalan que los cambios acelerados en la cantidad de créditos - incrementos -, se asocian con una función ineficiente de los intermediarios, por la que la calidad de los créditos es menor, llevando a aumentar las pérdidas en el sector bancario y provocar una crisis financiera.

Por otra parte, está la idea sobre cómo los mercados de valores integrados de manera global hacen que el riesgo se distribuya, induciendo a un cambio de cartera de inversión segura, pasando de un bajo rendimiento a una inversión de alto rendimiento, acelerando un crecimiento en la productividad. Sin embargo, la visión de creer mejor predictor a los mercados de valores tiene un debate que pone en duda dicho argumento; Shleifer y Vishny (1986), y Bhide (1993) objetan cómo un aumento de la liquidez facilita la venta de acciones, pero esto reduce los incentivos de los accionistas para asumir los costos de supervisión, debilitando al gobierno corporativo e impidiendo la asignación efectiva de recursos, lo cual retrasa el crecimiento.

En contraste con lo anterior, Baron y Xiong (2017), analizan la expansión crediticia sobre la perspectiva de los accionistas bancarios, es decir, las expectativas de los inversionistas sobre los mercados financieros, el conocimiento (información) y las perspectivas de los inversores que comercian y tienen acciones; en ese sentido, Schularick y Taylor (2012), señalan que una caída del capital bancario provocado por una expansión de crédito no implica rendimientos por debajo del promedio por parte de los accionistas, por lo tanto, les es difícil prever una caída por dicho fenómeno; entonces, los accionistas no reconocen el riesgo asumido por los banqueros, por lo cual la situación no va en contra de su voluntad, pero, por los momentos de euforia económica puede ser alentado por los mismos (Cheng, Hong y Scheinkman, 2015).

Las dos líneas sobre la cual se basa los efectos del sistema financiero sobre una economía, tienen puntos a favor y en contra, haciendo denotar que el debate sigue vigente. Sin embargo, el presente documento pretende acentuar desde la perspectiva del crédito bancario otorgado en una economía. En ese sentido, se parte de la hipótesis de King y Levine (1993) sobre la conexión independiente entre el mercado de valores y el sector bancario con el crecimiento económico, aseverando que los sistemas financieros más relacionados con el sector privado brindan mejores resultados para la economía; asimismo, encontraron que los niveles más altos de desarrollo financiero están asociados positivamente con las tasas más altas de crecimiento, acumulación de capital fijo y mejoras en la eficiencia económica, siempre que se cumpla con políticas económicas asequibles.

En cuanto al crédito bancario, también existe, en la actualidad, literatura sobre el papel del crédito en una economía; expansión de crédito no siempre genera mejoras en el crecimiento económico, donde un momento de euforia económica puede incrementar los montos crediticios otorgados, sin un síntoma de progreso en la economía, y generando una crisis financiera, tal como lo señalan Miao y Wang (2017), Martín y Ventura (2012), Culp, Nozawa y Veronesi (2018), Zhang, Zhai y Sun (2019) y Mah y Yoon (2020); en esta línea, León y Alvarado (2015), Arcand, Berkes y Panizza (2015) y Clavellina (2013), destacan una relación inversa entre el financiamiento y el crecimiento económico, porque en algunos casos el crédito bancario otorgado al sector privado puede alcazar el $100 \%$ del PIB, o por la existencias de oligopolios bancarios que limitan la generación de crédito; Cecchetti y Kharroubi (2012) y Krinichansky y Sergi (2019), encontraron un punto de inflexión entre 
el financiamiento y una mejora de la economía, lo que torna a una relación inversa entre dichas variables, pues a mayor crecimiento del sector bancario, más lenta de vuelve la economía. Por otro lado, otros autores relacionan de manera positiva el crédito y el crecimiento económico, siempre que éste vaya dirigido al sector privado (Geršl y Seidler, 2010; Fieldhouse, Mertens y Ravn, 2018; Guerrieri y Lorenzoni, 2017; Agarwal, Chomsisengphet, Mahoney y Stroebel, 2018; Barriga, González, Torres, Zurita y Pinilla, 2018; Kärnä, 2019; Torre y Flores, 2020).

Por último, y no menos importante, existe otra visión sobre la relación entre las finanzas y la mejora de una economía, en el cual Law y Singh (2013) y Masuduzzaman, Parveen, Islam y Dipty (2019), argumentan que se da de forma no lineal, asemejándose más una función cuadrática de maximización, donde hay un clímax sobre el efecto de financiamiento en la economía, y al pasar dicho umbral sus efectos de transforman en rendimientos decrecientes. En otras palabras, el sector financiero, a través de los créditos, tiene un papel importante para lograr efectos positivos en la economía, pero existe un nivel óptimo de crecimiento en los recursos financieros para las actividades productivas, el cual depende del papel que desarrollen los intermediarios financieros.

Antecedentes

Dentro de esta sección, se revisa el comportamiento del crédito bancario, emitido por la Banca Comercial y la Banca de Desarrollo, otorgado a los sectores productivos y consumo; asimimso, lo ocurrido con el PIB mexicano en dicho periodo. En ese sentido, el apartado se divide en 2: el primero, el crédito bancario otorgado a los sectores productivos y al consumo; y el segundo, el comportamiento del PIB en México.

El crédito bancario otorgado a los sectores productivos y al consumo

Este análisis sobre el comportamiento del crédito bancario otorgados al sector industrial y al consumo en México, provienen del banco de datos del INEGI, con la intenión de medir la relación con el crecimiento económico. Aunque el trabajo hace explícito que se toman como variables explicativas los montos crediticios bancarios concedidos al sector industrial y al consumo, se toman también los conferidos al agropecuario, servicios y vivienda, con fines de hacer más robustas las gráficas.

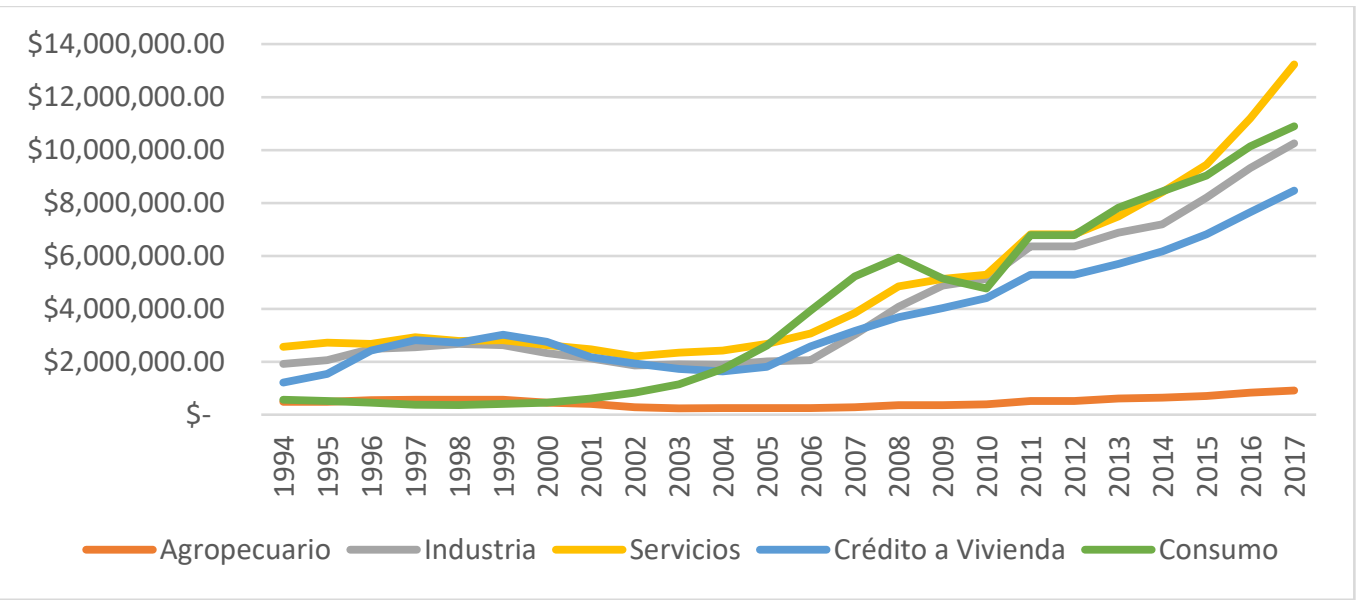

Figura 1. Crédito otorgado por la Banca Comercial a las actividades productivas y al consumo en México, en millones de pesos: 1994-2017.

Fuente: elaboración propia con datos del BIE del INEGI (inegi.org.mx).

Nota: las cifras son constantes con año base en 2013; las variaciones porcentuales se pueden ver en Anexo 1. 
Como se puede observar en la Figura 1, la distribución del crédito de la Banca Comercial en México tuvo comportamiento atípico, en un lapso de 24 años; el financiamiento a los sectores productivos fue disminuyendo, mientras que el financiamiento al consumo - un sector no productivo - se incrementó, pasando del $8.33 \%$ en el 1994 al $24.9 \%$ en el 2017 del total de financiamiento otorgado por la Banca Comercial.

Entre 1994 y 2000, la distribucón del credito comercial tiene como pilar principal al sector servicios, seguidos de la vivienda y el sector industrial; en dicho periodo, el crédito al consumo no era tan importante, oscilando su participación entre 8 y 5 por ciento. Durante el sexenio de Vicente Fox, entre el 2003y 2006, quisieron sentar un crecimiento económico en la industrialización; el sector industrial tuvo un aumento del $5 \%$ en montos crediticios otorgados, pasando de \$ 1'902,432 millones de pesos en el 2003 a $\$ 2$ '063,563 millones en el 2006, aunque en cuanto a participación respecto al total del crédito tuvo una caída - pasó del $25.83 \%$ al $17.37 \%$, respectivamente. Un fenómeno muy vistoso en ese periodo (2003-2006), fue el impulso a los créditos de consumo, los cuales se dispararon en dicho periodo; empezando con el $15.63 \%$ (\$1'151,156.4 millones de pesos) de los créditos totales, culminando con un incremento de 17.44 puntos porcentuales, es decir, tuvo una representación del 33.07 por ciento (\$3'927,291.1millones de pesos) de los créditos totales otorgados por la banca privada.

La participación del Consumo en la distribución de los créditos otorgados por la Banca Comercial, tomó un papel imperante entre el 2006 y el 2008 - la representación osciló por enciam del 30\% -, superando al sector servicios y a la industria; no obstante, el boom del crédito bancario al consumo avisaba la llegada de una crisis financiera y, con ello, una caída de la representatividad en la distribución de los montos de crédito - pasó de 31.42\% (\$5'930,913.00), en el 2008, a 23.85\% (\$4'760,613.20), en el 2010 -. En los próximos 7 años, del periodo de estudio, del 2011 al 2017, el crédito al consumo se recupera, jugando el primer lugar de representatividad en la distribución de los montos crediticios con el sector sevicios, dejando en el tercer puesto al sector industrial.

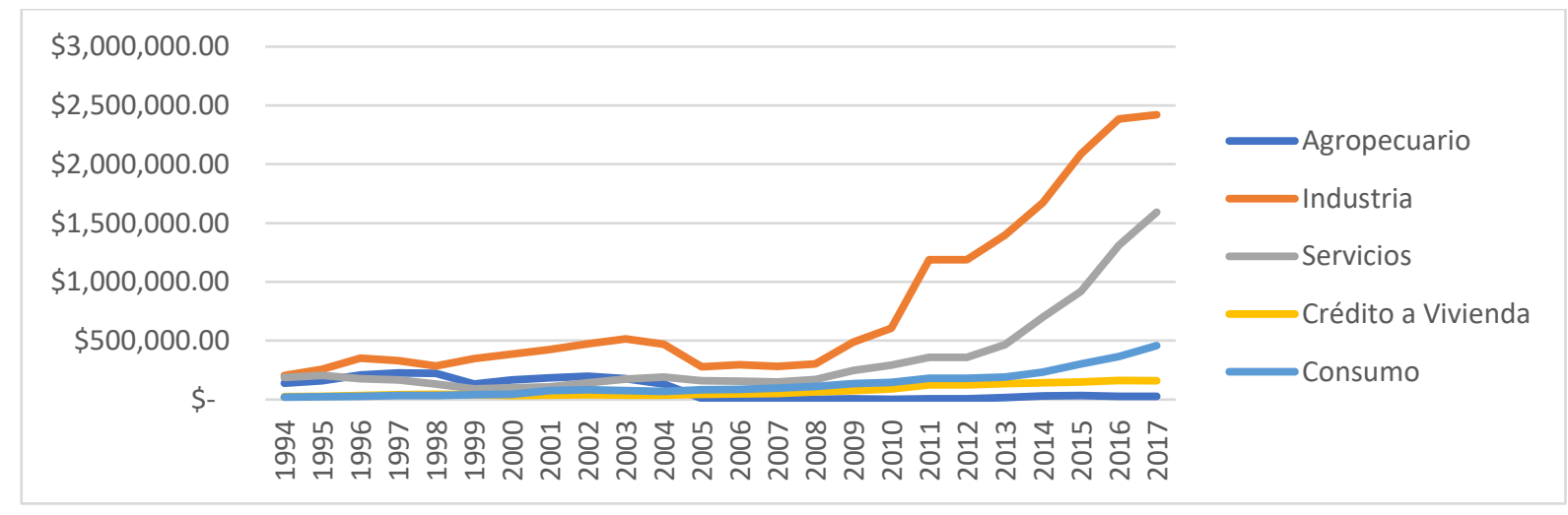

Figura 2. Crédito otorgado por la Banca de Desarrollo a las actividades productivas y al consumo en México, en millones de pesos: 1994-2017.

Fuente: elaboración propia con datos del BIE del INEGI (inegi.org.mx).

Nota: las cifras son constantes con año base en 2013; las variaciones porcentuales se pueden ver en Anexo 2. 
En el caso del crédito otorgado por la Banca de Desarrollo, como se observa en la Figura 2, presentó un cambio en la distribución de los montos, siendo el sector primario el más perjudicado; de tener una participación del 24.28 por ciento ( $\$ 139,104$ millones de pesos) en 1994, bajó a 0.57 por ciento (\$26,328.70 millones de pesos) en el 2017. Los servicios tuvieron un incremento porcentual entre 1994 y 2017; pasando de 32.43 a 34.19 por ciento, mas en el monto hubo un descenso pasando de $\$ 14,444.43$ millones a $\$ 11,348.33$ millones. Mientras que el consumo casi triplicó su participación, de tener el 3.44 por ciento $(\$ 19,706.4$ millones de pesos) de los créditos de la banca pública en el 1994, obtuvo el 9.83 por ciento en el 20017 (\$457,968 millones de pesos).

Por parte de la Banca de Desarrollo, el sector industrial fue el más favorecido con créditos otorgados; la representatitividad de los montos concedidos a la industria pasaron a ser el 34. 25\% (\$204,060.00 millones) en 1994, al 46.66\% (\$2'420,915.60) en el 2017. Entre el 2004 y el 2017, la distribución de estos créditos, favorecieron a la industria, a los servicios y al consumo, en ese orden.

No obstante, hay una diferencia muy marcada entre los montos crediticios otorgados por la Banca de Desarrollo y la Baca Comercial, tanto al consumo como al sector industrial. Para el caso del Sector Industrial, los montos concedidos por la Banca de Desarrollo representarón, en promedio, el 17\% de los montos conferidos por la Banca Comercial (Veáse Figura 3). Una situación muy similar ocurrió con los préstamos al consumo, donde los montos provenientes de la Banca del Desarrollo equivalían al 5\%, en promedio, de los otorgados por la Banca Comercial (Veáse Figura 4).

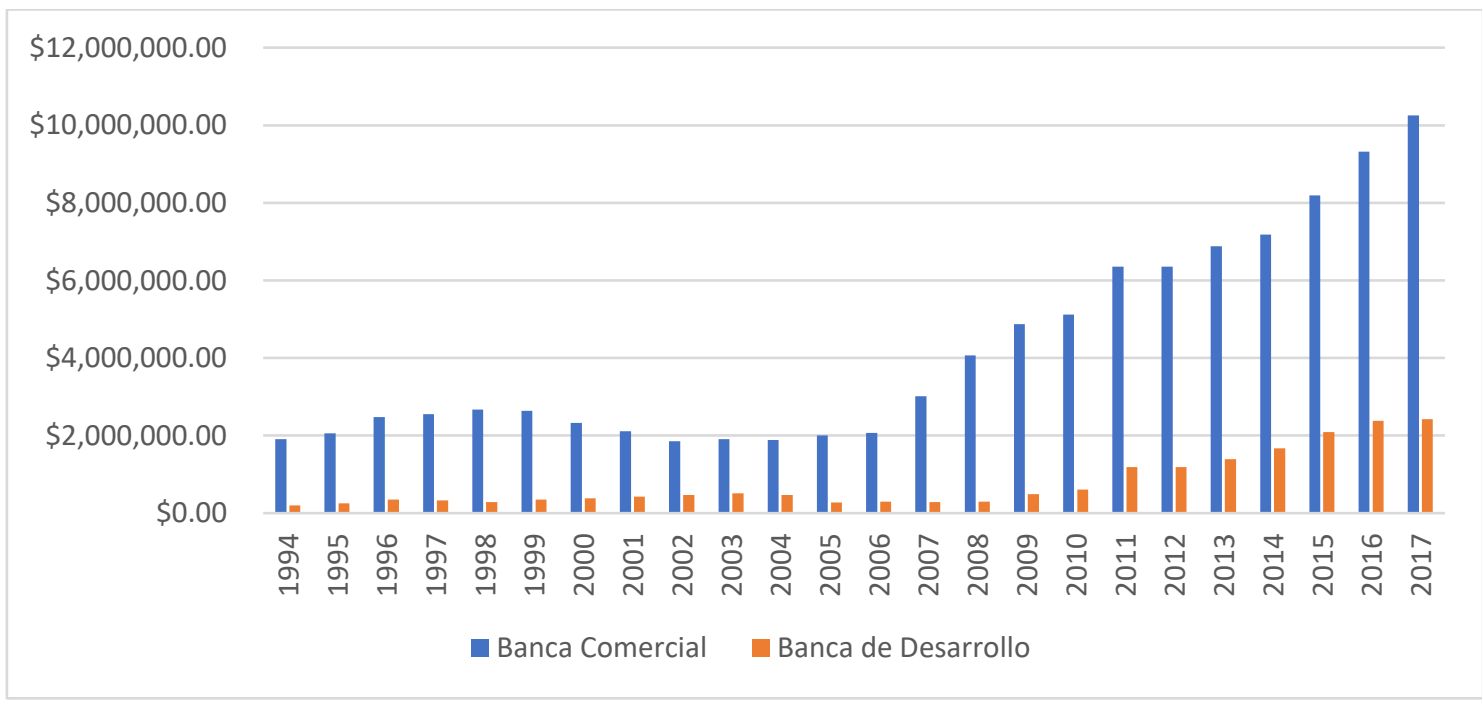

Figura 3. Crédito Bancario otorgado al Sector Industrial, en millones de pesos: 1994-2017. Fuente: elaboración propia con datos del BIE del INEGI (inegi.org.mx). Nota: las cifras son constantes con año base en 2013. 


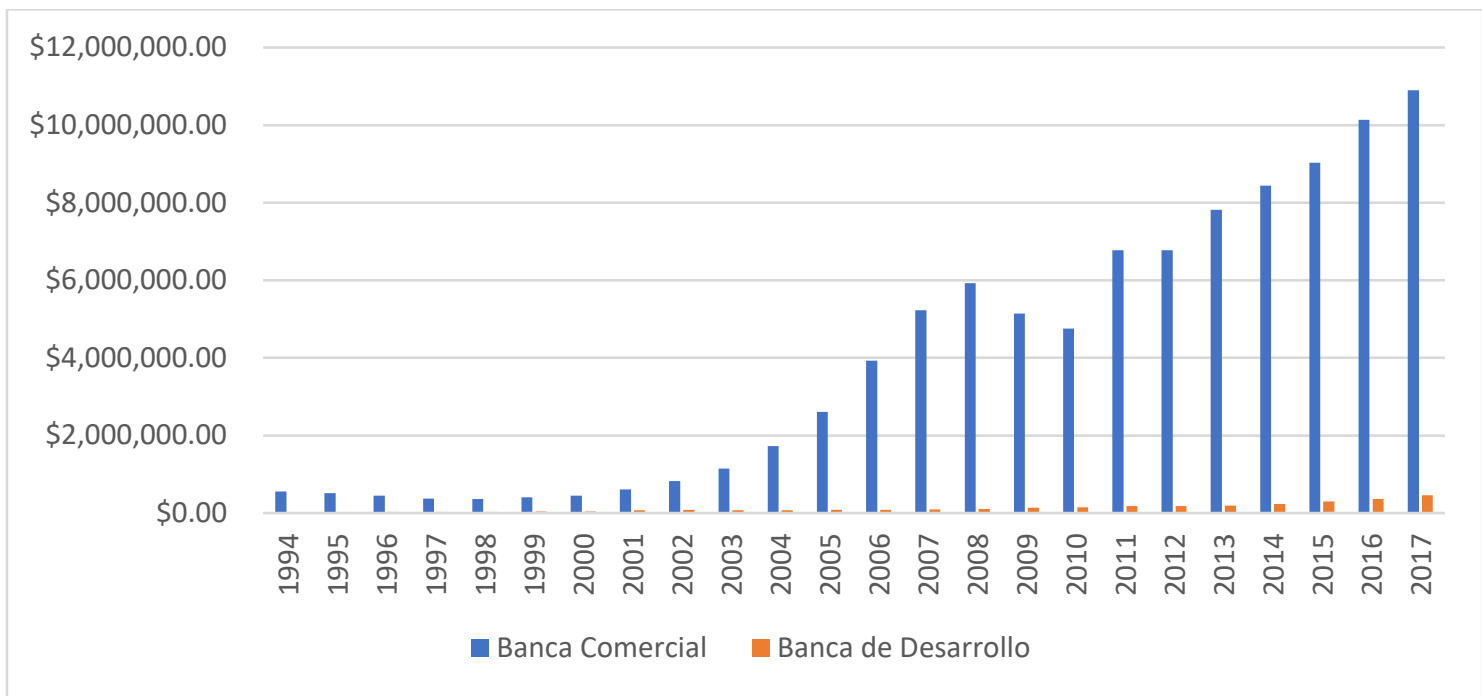

Figura 4. Crédito Bancario otorgado al Consumo, en millones de pesos: 1994-2017. Fuente: elaboración propia con datos del BIE del INEGI (inegi.org.mx).

Nota: las cifras son constantes con año base en 2013.

\section{El comportamiento del PIB en México}

En esta subsección se utiliza la información correspondiente del PIB real de México, el cual proviende del INEGI, con la finalidad de analizar el crecimiento económico del país, en un lapso de 24 años, 1994-2017. Anque los datos están en montos, para efectos de visualización de las fluctuaciones del crecimiento, la Figura 5 presenta el comportamiento del PIB real en puntos porcentuales.

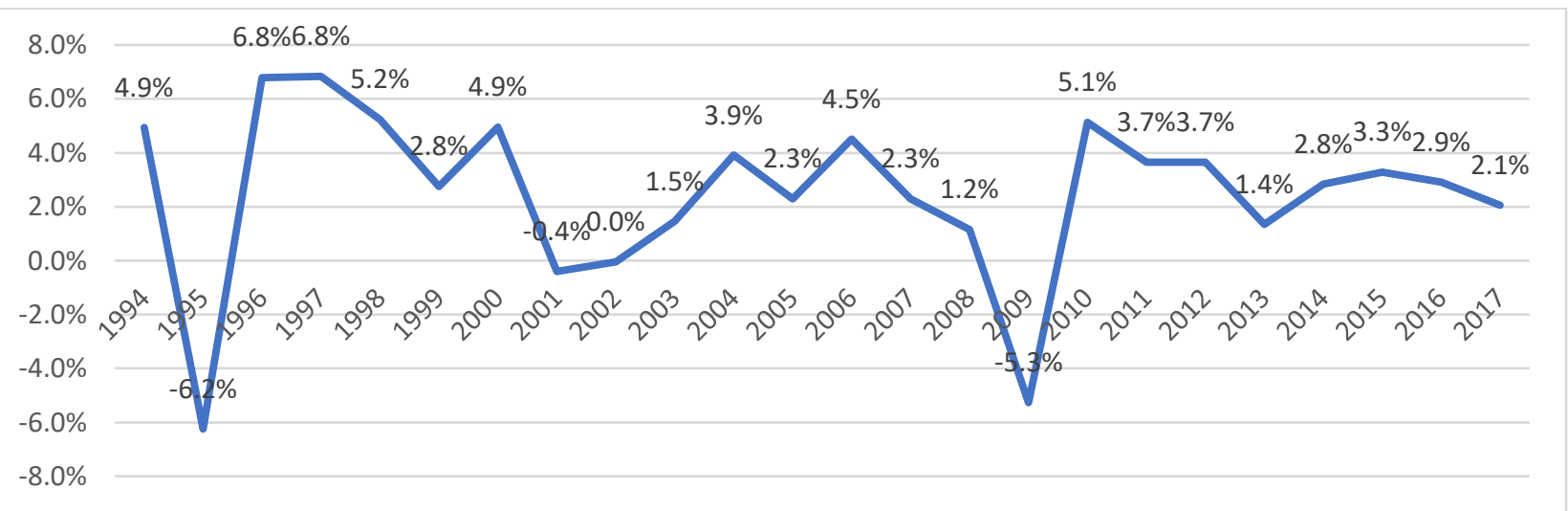

Figura 5. Comportamiento del PIB real en México, 1994-2017. Fuente: elaboración propia con datos del INEGI (inegi.org.mx).

*Año base 2003.

El crecimiento económico que tiene México entre 1994 y el 2017, según la figura anterior, tiene un comportamiento accidentado, ya que refleja fluctuaciones muy pronunciadas, las cuales se 
deben a momentos de inestabilidad económica que a continuación señalaremos. Antes de la crisis financiera de diciembre de 1994, mejor conocida como "El error de diciembre", la economía mexicana presentó un crecimiento de casi 5 puntos porcentuales; no obstante, cayó 11.2 puntos porcentuales. La recuperación, entre 1996 y 2000, se dio por una estrategia impuesta por el FMI; ésta consistió en pedir préstamos al FMI y otros países, con la intención de estabilizar la economía y recuperar la confianza de los inversores extranjeros, con la condición de mejorar el balance fiscal, generar buenas reservas internacionales y estabilizar la inflación - la cual no debía de pasar el 5\% anual - (Cruz y Lapa, 2012); esto ayudo generar un crecimiento constante entre 1996 y el 2000, en promedio, el PIB creció a una tasa del $5.3 \%$ anual durante ese periodo

En el 2001, la economía méxicana venía arrastrando una caída del crecimiento económico, la cual se le atribuye como efecto del sector exterior; la economía estadounidense sufría una desaceleración de su economía, y México con una dependencia comercial con el mercado estadounidense, desató efectos negativos para la economía mexicana (Calva, 2001). No obstante, la economía mexicana presentó mejoría entre el año 2002 y el 2006, la cual se debió a una mejoría del mercado estadounidense, la cual incentivó las exportaciones y, de manera interna, un aumento en el gasto público.

Entre el 2007 y el 2009, el crecimiento económico en méxico fue en caída, lo cual se debió a los efectos de la crisis financiera mundial; la economía estadounidense se paralizó por la quiebra de la banca de inversión, como efectos de la explosión de la burbuja inmobiliaria - los bancos estadounidenses saturaron el mercado de los créditos hipotecarios, generando carteras vencidas altas -. La desaceleración de la economía estadounidense impactó y desestabilizó a la economía mexicana; una vez más, la afectación se dio por una baja en el sector exportador, debido el fuerte vínculo comercial entre los mercados de ambos países - Estados Unidos y México -. Esto generó presiones en el tipo de cambio, a la cual Banxico reajusto la paridad peso-dólar en 30\%, es decir, la política monetaria entró en vigor con una devaluación frente al dólar (Gonzáles et al., 2009).

Después de la abrupta caída de la economía mexicana, a consecuencia de la crisis financiera mundial del 2008, ésta tuvo un repunte en el 2010, con un crecimiento de 10.4 puntos porcentuales, es decir pasó de $-5.3 \%$, en el 2009, a 5.1\%, en el 2010; una tenue recuperación de la economía estadounidense, lo que activó al sector exportador mexicano; asimismo, la Inversión Extranjera de Cartera (IEC) jugó un papel importante, pues a diferencia de la Inversión Extranjera Directa (IED), pues incrementó su participación en la economía mexicana (Romero y Minto, 2010).

Entre 2011 y el 2017, la economía mexicana se contrajo respecto al repunte del 2010, sin importar que la inflación de mantuvo considerablemente estable, oscilando entre 2 y 3 puntos porcentuales. En el 2011, la guerra contra el narcotráfico tuvo efectos secundarios sobre la economía; la inseguridad que ésta generó, reprimió la inversión y, por lo tanto, a la inversión extranjera. Entre el 2012 y el 2017, la economía mexicana siguió mostrando una desaceleración económica, debido a caídas del sector terciario y el sector industrial causada por el sector exterior, es decir, sus socios comerciales no lograban salir de los estragos de la crisis financiera del 2008 (OCDE, 2017). 


\section{Metodología}

\subsection{Especificación del modelo}

El objetivo de este artículo es medir los efectos de los créditos bancarios, otorgados al sector industrial y al consumo, sobre el crecimiento económico. El estudio utiliza datos trimestrales del PIB, PIB industrial, crédito bancario al consumo, crédito bancario a la industria, todos ellos de México. Se seleccionó un periodo de 24 años, el cual corresponde de 1994 al 2017, un lapso importante de la economía mexicana, ya que se relaciona con la entrada del TLCAN y se cruza la crisis financiera mundial del 2008.

Con base en la literatura empírica existente, se puede especificar la existencia de una relación entre el desarrollo financiero, desde una perspectiva del crédito bancario, y crecimiento económico, donde al largo plazo puede surtirefectos positivos (Greenwood y Jovanovic, 1990; Bencivenga y Smith, 1991; King y Levine, 1993; Zhang, Wang y Wang, 2012; Zafar, Ahmad y Hussain, 2012; Geršl y Seidler, 2010; Fieldhouse, Mertens y Ravn, 2018; Guerrieri y Lorenzoni, 2017; Támará y Castellón, 2017). Así, se toma en cuenta la idea de Levine (1998), quien define al desarrollo bancario como el crédito asignado por los bancos al sector privado.

Una regresión de series de tiempo ha sido utilizada en estudios de recientes sobre desarrollo financiero y su relación con el crecimiento económico (Agarwal, Chomsisengphet, Mahoney y Stroebel, 2018; Akosah, 2013; Korkmaz, 2015; Torre y Flores, 2020). Hay varias ventajas de utilizar un modelo de series de tiempo; primero, es un estudio para analizar la relación entre el crédito bancario, otorgado a la industria y al consumo, y el crecimiento económico en un país en específico (México), lo cual lo hace idóneo; segundo, la base de datos es en un periodo de 24 años (1994-2017), con 96 datos - trimestral cada uno - para cada variable; y tercero, se analiza si existe un cambio o coyuntura en los efectos del crédito bancario - tanto el otorgado al sector industrial como al consumo - después de la crisis financiera del 2008. En ese sentido, la mayoría de los análisis de series de tiempo para el crecimeinto económico y su relación con el desarrollo financiero o bancario estan basado en los modelos autoregresisvos, tanto de primer y segundo orden como de "p" orden:

$$
\begin{gathered}
\left(Y_{t}-\delta\right)=\alpha_{i}\left(Y_{t-1}-\delta\right)+u_{t} \\
\left(Y_{t}-\delta\right)=\alpha_{1}\left(Y_{t-1}-\delta\right)+\alpha_{2}\left(Y_{t-2}-\delta\right)+u_{t} \\
\left(Y_{t}-\delta\right)=\alpha_{1}\left(Y_{t-1}-\delta\right)+\alpha_{2}\left(Y_{t-2}-\delta\right)+\cdots \alpha_{p}\left(Y_{t-p}-\delta\right)+u_{t}
\end{gathered}
$$

No obstante, la propuesta de esta investigación, recae en un modelo AR(1) multivariante, con variable dicotómica; ésta última para constatar la existencia de un posible cambio estructural de los efectos del crédito bancario, dirigido al sector industrial y al consumo, sobre el crecimiento económico después dela crisis financiera del 2008. En ese sentido, el modelo propuesto es: 


$$
\operatorname{PIB}_{t}=\beta_{0 t}+\beta_{1} \operatorname{CIND}_{t}+\beta_{2} \operatorname{CCONS}_{t}+\beta_{3} I M P K_{t}+\beta_{4} E X P O_{t}+\beta_{5} B A 2008_{t}+\mu_{t}
$$

En la ecuación (4) se emplea el Producto Interno Bruto (PIB) como variable dependiente. Las variables independientes son: el crédito bancario otorgado a la industria (CIND), el cual es uno de los indicadores más utilizados por expertos en la materia de crecimiento y desarrollo financiero, tal como Levine (1997; 1998), King y Levine (1993), Fieldhouse, Mertens y Ravn (2018); el crédito bancario al consumo (CCONS), siendo una parte importante para la activación de la economía de un país, por lo tanto, incentivar el consumo es sano (García y Han, 2015), sin embargo, Geršl y Seidler (2010) argumentan que la expansión del crédito mal enfocado, es decir, dirigido a incrementar el consumo (demanda agregada), sólo ocasionaría problemas de inflación, un sobre calentamiento de la economía; las exportaciones (EXPO) y las importaciones de bienes de capital (IMPBK) son variables de control, las cuales sirven para eliminar o neutralizar posibles efectos en el análisis sobre el crecimiento económico, ya que no son objeto de estudio para la presente investigación. Estas variables, en conjunto, representan a posibles factores de impacto sobre el crecimiento de una economía, tal como lo han señalado expertos sobre el tema (Schumpeter, 1912; McKinnon, 1973; Shaw, 1973; Geršl y Seidler, 2010; Fieldhouse, Mertens y Ravn, 2018; Guerrieri y Lorenzoni, 2017; Agarwal, Chomsisengphet, Mahoney y Stroebel, 2017; Torre y Flores, 2020).

Como ya se ha mencionado, la intención es analizar si hay algún cambio. En ese sentido, al modelo se les anexará la variable de tendencia $(t)$ y una variable dicotómica para entender los cambios que pueden darse después de la crisis financiera mundial del 2008 (BA2008); donde la primera, ayuda a caracterizar el patrón gradual y consistente de las variaciones de la propia serie, las cuales pueden afectar al mismo modelo, y ayuda a eliminar correlaciones espurias de series de tiempo; y la segunda, toma valores de 0 antes del 2008 (1994-2007) y de 1 del 2008 en adelante (2008-2017). Esto, con la finalidad de medir las posibles variaciones que estás ocasionan al incorporarlos a la regresión. Bajo esa idea, la ecuación queda de la siguiente forma:

$$
P I B_{t}=\beta_{0 t}+\beta_{1} \operatorname{CIND}_{t}+\beta_{2} \operatorname{CCONS}_{t}+\beta_{3} I M P K_{t}+\beta_{4} E X P O_{t}+\beta_{5} B A 2008_{t}+\beta_{6} t_{t}+\mu_{t}
$$

Cabe mencionar que los datos tienen la aplicación de logaritmo natural para las regresiones, pues es posible la existencia de una relación no lineal entre el crecimiento y las variables explicativas - a excepción de t y B/A2008, puesto que son la tendencia secular y la variable dicotómica -. Entonces, los modelos tienen la siguiente forma:

$$
\begin{aligned}
& \ln P I B_{t}=\beta_{0 t}+\beta_{1} \ln C I N D_{t}+\beta_{2} \operatorname{lnCCONS_{t}}+\beta_{3} \operatorname{lnIMPK_{t}}+\beta_{4} \ln E X P O_{t}+ \\
& \beta_{5} B A 2008+\beta_{6} t_{t}+\mu_{t}
\end{aligned}
$$

Asimismo, la variable dicotómica se multiplica por las variables de crédito bancario al consumo (CCONS) y crédito bancario a la industria (CIND), con la intensión de entender si existe un cambio con el comportamiento de ambas variables después de la crisis financiera del 2008, y en los efectos que generan sobre el crecimiento económico:

$$
\begin{aligned}
& \operatorname{lnPIB}_{t}=\beta_{0 t}+\beta_{1} \operatorname{lnCIND}_{t}+\beta_{2} \operatorname{lnCCONS}_{t}+\beta_{3} \operatorname{lnIMPK_{t}}+\beta_{4} \ln E X P O_{t}+\beta_{5} B A 2008_{t}+\beta_{6} t_{t}+ \\
& \beta_{7} B A 2008 * \operatorname{lnCIND} D_{t}+\beta_{8} B A 2008 * \operatorname{lnCCONS} S_{t}+\mu_{t}
\end{aligned}
$$




\subsection{Variable y fuente de datos}

Las series de datos utilizadas en este estudio, data de un periodo de 24 años, desde el primer trimestre de 1994 hasta el cuarto trimestre del 2017, siendo 96 observaciones trimestrales de cada una de las variables tomadas. Los datos sobre cada variable se tomaron del Instituto Nacional de Estadísticas y Geografía (INEGI), Banco de Información Económica (BIE); no obstante, los datos fueron descontinuados en INEGI, por lo cual imposibilita añadir observaciones posteriores al año 2017. El PIB es la variable dependiente, está expresada en términos reales y en millones pesos con años base 2013 (=100); de igual manera, el crédito bancario al consumo y el crédito bancario a la industria, utilizando como años base el $2018(=100)$ y $2012(=100)$, respectivamente. No obstante, las exportaciones e importaciones de bienes de capital están dado en millones de dólares, para lo cual se hizo una conversión con un promedio de tipo de cambio a lo largo del periodo de estudio, y después se tornaron a datos reales, tomando como base el índice de precios, respectivos, del año 2005 (=100) y 1980 (=100), respectivamente. Como ya se ha hecho mención, dentro del lapso de estudio se encuentran sucesos importantes para la economía, como lo es la entrada en vigor del Tratado de Libre Comercio de América del Norte en 1994, y la crisis financiera mundial del 2008.

\subsection{Predicciones de los modelos}

Atendiendo la literatura revisada, el CIND debe tener una relación positiva tanto con el PIB, pues un crédito dirigido a uno de los sectores productivos, la industria, genera la compra de insumos y bienes de capital para expandir su producción, llevando, también, un posible incremento del capital humano (Bagehot, 1873; Schumpeter, 1912; McKinnon, 1973; Shaw,1973; Greenwood y Jovanovic, 1990; Bencivenga y Smith, 1991; King y Levine, 1993 Levine, 1991; Bencivenga et al.,1995; Gurley y Shaw,1955; Khan y Senhadji, 2003; Geršl y Seidler, 2010; Zafar et al., 2012; Fieldhouse, Mertens y Ravn, 2018; Guerrieri y Lorenzoni, 2017; Agarwal, Chomsisengphet, Mahoney y Stroebel, 2017; Sreerama, Sailaja y Mullugeta, 2012; Barriga, González, Torres, Zurita y Pinilla, 2018: Torre y Flores, 2020).

Para el caso del CCONS, es una de las variables más inciertas en su comportamiento, debido a la tendencia de los estudios donde se considera que un incremento del crédito a los sectores no productivos puede ocasionar desaceleración económica, e incluso un boom desmedido en el corto plazo puede llegar a desencadenar crisis financieras (Miao y Wang, 2017; Geršl y Seidler, 2010; Martín y Ventura, 2012; Clavellina, 2013; Armeanu, Pascal, Poanta y Doia, 2015; Culp, Nozawa y Veronesi, 2018). Bajo ese enfoque, se considera un impacto negativo del crédito al consumo sobre el PIB, sin embargo, no se debe descartar la idea sobre la importancia del consumo en la economía, y en una proporción es buena para el crecimiento.

Por último, las variables BA2008*InCCONS y BA2008*InCIND deben predecir algún cambio en los efectos del crédito bancario otorgado al consumo y del crédito bancario otorgado a la industria, después de la crisis financiera mundial del 2008, donde los países tomaron medidas anticrisis políticas para regular la economía -, entre ellos, México. No obstante, en el caso de México, las medidas anti-crisis fueron políticas contractivas, muy parecidas a las utilizadas en la década de 1980, 
como recortes, más impuestos y el anuncio de sacrificios "necesarios", traduciéndose en un bajo crecimiento económico y el incremento de los problemas socioeconómicos del país; es decir, las medidas generaron más desempleo y menos financiamiento para las actividades productivas, mientras que el financiamiento al consumo lo afecto muy poco (Ortiz, 2009). Bajo esta idea, se puede augurar que el crédito otorgado a la industria después del 2008 no genera efectos positivos sobre la economía, puesto que las empresas, aunque reciban financiamiento, no se arriesgan a invertir; por el lado del consumo, si se mantiene el financiamiento, es para incentivar la demanda y reactivar a la economía, por lo tanto, el financiamiento al consumo debe de generar efectos positivos sobre la economía después de la crisis del 2008.

De esta manera, y atendiendo los párrafos anteriores, se puede deducir que el modelo podría tener las siguientes relaciones entre sus variables:

$$
\begin{aligned}
& \ln P I B_{t}=\beta_{0 t}+\beta_{1} \operatorname{lnCIND}_{t}+\beta_{2} \operatorname{lnCCONS}_{t}+\beta_{3} \operatorname{lnIMPK_{t}}+\beta_{4} \ln E X P O_{t}+\beta_{5} t+\beta_{6} B A 2008- \\
& \beta_{7} B A 2008 * \operatorname{lnCIND_{t}}+\beta_{8} B A 2008 * \operatorname{lnCCON} S_{t}+\mu_{t}
\end{aligned}
$$

\subsection{Resultados empíricos}

En esta sección, se discuten los hallazgos del estudio y los resultados empíricos que arrojó el modelo con Eviews 11. Primeramente, se presentan los productos derivados de la prueba de regresión espuria; en segundo lugar, la prueba de estacionaridad y cointegración; en tercer lugar, la verificación de la existencia de una relación a largo plazo entre las variables.

De acuerdo a Woodridge (2010), en un modelo de regresión series de tiempo a largo plazo, es muy probable la existencia de una regresión espuria; es decir, la regresión aparenta ser adecuada, ya que presenta una correlación muy alta entre sus variables, pero sus series no son estacionarias. En ese sentido, se comparan los indicadores $\mathrm{R}^{\wedge} 2$ y Durbin-Watson (DW) bajo las siguientes premisas: la hipótesis nula (Ho) señala que si $\mathrm{R}^{\wedge} 2$ es mayor que $\mathrm{DW}$, es muy probable que se trate de una regresión espuria; la hipótesis alternativa (H1), argumenta que si $\mathrm{R}^{\wedge} 2$ es menor a DW, no es una regresió espuria.

\begin{tabular}{|c|c|c|c|}
\hline $\mathrm{R}^{\wedge} 2>\mathrm{DW}$ & \multicolumn{3}{|c|}{ Ho: Hay indicios de una regresión espuria } \\
\hline $\mathrm{R}^{\wedge} 2<\mathrm{DW}$ & \multicolumn{3}{|c|}{ H1: No hay indicios de una regresión espuria } \\
\hline & $\overline{\mathrm{R}^{\wedge} 2}$ & $<$ & DW \\
\hline & 0.989893 & & 1.819938 \\
\hline
\end{tabular}

Tabla 1. Deteminación de sospecha de una regresión espuria

Fuente: elaboración propia con datos del BIE del INEGI, con el program Eviews 11.

Como se observa en la Tabla 1 los resultadado arrojan que el coeficiente $\mathrm{R}^{\wedge} 2$ es menor que el indicador DW, por lo cual se rachaza la hipótesis alternativa (Ho) y, por ende, no hay sospechas de tratarse de una regresión espuria. Con la intención de sustentar estos resultados, se procede a comprobar si las variablse son o no son estacionarias con la prueba de raíz unitaria.

La prueba de Raíz Unitaria con la metodología de Engle y Granger, de acuerdo a Guajrati y Porter (2010) y Woodridge (2010), se trata de un análisis de integración en las variables que 
comprende al modelo de regresión, con el objetivo de comprobar si cada una de ellas cumplen con la condición de ser estacionaria en primer orden, lo cual denotaría la cointegración. La prueba emplea la comprobación de raíces unitarias con el test Dickey-Fuller para cada una de las variables, donde tienen que ser de raíz unitaria en sus primeros niveles, y estacionarias en la primera diferencia.

Tabla 2. Prueba de Raíz Unitaria

\begin{tabular}{|l|r|r|c|c|}
\hline Ho: Tiene raíz unitaria y no es estacionaria \\
\hline H1: Es estacionaria en su primera diferencia \\
\hline \multicolumn{5}{|c|}{ Resultados en los primeros niveles } \\
\hline Variable & t-calculada & t-estadística & Prob. & Acep. H \\
\hline PIB (lnPIB) & -0.91854 & -3.503879 & 0.7782 & Ho \\
\hline Crédito al Consumo (lnCCONS) & -1.392965 & -3.503049 & 0.5825 & Ho \\
\hline Crédito a la Industria (lnCIND) & -1.657288 & -3.501445 & 0.4495 & Ho \\
\hline \multicolumn{5}{|c|}{ Resultados en su primera diferencia } \\
\hline Variable & t-calculada & t-estadística & Prob. & Acep. H \\
\hline PIB (lnPIB)*** & -4.241475 & -3.503879 & 0.001 & H1 \\
\hline Crédito al Consumo (lnCCONS) ${ }^{* * *}$ & -3.522446 & -3.503049 & 0.0094 & H1 \\
\hline Crédito a la Industria (lnCIND)*** & -4.91274 & -3.501445 & 0.0001 & H1 \\
\hline
\end{tabular}

Nota: *, ** ${ }^{* * *}$ indican la significación estadística al nivel del 10\%, 5\% y 1\%.

Fuente: elaboración propia con datos del BIE del INEGI, con el program Eviews 11.

De acuerdo a los resultados de la Tabla 2, se observa que las tres variables de importancia para el presente estudios - PIB (lnPIB), Crédito otorgado al Consumo (lnCCONS) y el crédito otorgado al Sector Industrial (lnCIND) - presentan una raíz unitaria en sus primeros niveles, pero al hacer la prueba en sus primeras diferecias, cada una de las varibales de encuentran integradas en orden 1, con un nivel de significancia de 1\%. Estos resultados denotan que las variables estan cointegradas en la primera diferencia, y probablemente sirvan para determinar una relación en largo plazo. Con la intención de hacer más robusto la comprobación, se le hace la prueba de cointegración a los resuidos del modelo propuesto.

Prueba de cointegración: de acuerdo con Gujarati y Porter (2010) y Woodridge (2010), el test Dickey-Fuller sirve para saber si los residuos se comportan con alguna tendencia que denotan indicios de no estar integrados, ni ser estacionario en sus primeros niveles:

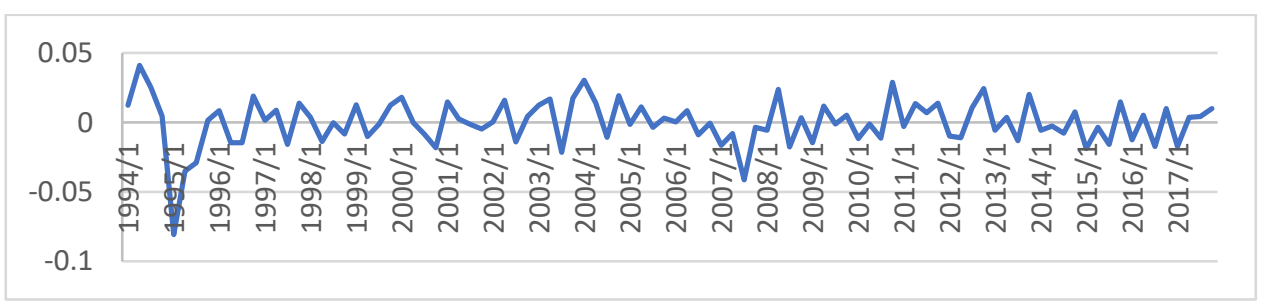

Figura 6. Comportamiento de los Residuos de la Ecuación (5).

Fuente: elaboración propia con datos del BIE del INEGI, con el program Eviews 11. 
Como se puede observar la Figura 6, los residuos en el largo plazo no presentan una tendencia, sino un comportamiento aleatorio. Esta caminata sin rumbo de los residuos en el largo plazo es una buena señal para el modelo, y sigue sosteniendo que no se trata de un regresión espuria; ahora, sólo falta comprobar que son estacionarios en orden cero. Para la prueba de estacionaridad, se aplica el tes Dickey-Fuller, donde se trata de comprobar que los residuos del modelo son estacionarios en orden cero. La hipótesis nula del test indica que, en caso de no ser significativo en sus primeros niveles, los residuos resultan con raíz unitaria y no estacionarios; por otro lado, la hipótesis alternativa señala que si los residuos son significativos, éstos son estacionarios y denotan que están integrados en sus primeros niveles:

Tabla 3. Prueba de Cointegracion

\begin{tabular}{|c|c|c|c|c|}
\hline \multirow{2}{*}{\multicolumn{5}{|c|}{ 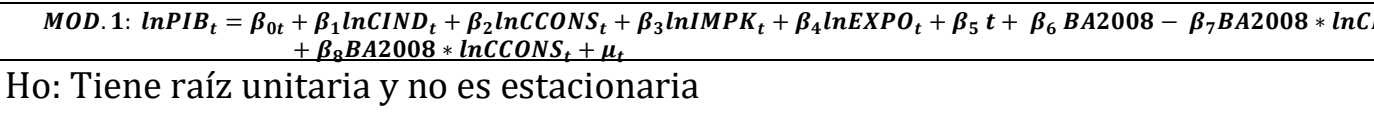 }} \\
\hline & & & & \\
\hline \multicolumn{5}{|c|}{ H1: Es estacionario en orden cero } \\
\hline \multicolumn{5}{|c|}{ Resultados en los primeros niveles } \\
\hline Variable & t-calculada & t-estadística & Prob. & Acep. H \\
\hline Residuos*** & -4.795888 & -2.59034 & 0.0000 & H1 \\
\hline
\end{tabular}

Nota: Esta tabla resume los resultados del enfoque de pruebas de límites para conocer la existencia de cointegración. Los valores críticos de la t-Tabla se toman de la tabla Davidson-McKinnon. El modelo contiene constante y tendencia. *,** ${ }^{* * *}$ indican la significación estadística al nivel del 10\%, 5\% y 1\%. Fuente: elaboración propia con datos del BIE del INEGI, con el program Eviews 11.

De acuerdo a la Tabla 3, los resultados señalan que los residuos no presentan una raíz unitaria y son estacionarios en orden cero, por lo tanto, de rechaza la hipótesis nula; es decir, los residuos están integrados y muestran que no se trata de una regresión espuria en el largo plazo. Con la intención de hacer más robusta la verificación de la existencia de una relación a largo plazo entre las variables del modelo presentado, correra una regresión de cointegración, con la intención de aplicar el test de Engle-Granger. De acuerdo a Gujarati y Porter (2010) y Woodridge (2010), la regresión de cointegración y el test de Engle-Granger, sirven para denotar la existencia de una relación a largo plazo entre la variables, y sirven para explicar el fenómeno deseado; en donde, alguno de los estadísticos calcullados, Tau o "Z", debe ser significativo.

Tabla 4. Cointegración a largo plazo

\begin{tabular}{|l|c|c|c|c|}
\hline \multicolumn{4}{|l|}{ Ho: Si Tau y "Z" no son significativo, no existe relación en largo plazo } \\
\hline H1: Si Tau o "Z" son significativos, existe relación en largo plazo \\
\hline Tipo de indicador estadístico & Valores & Prob. & Significativo & Acep. H \\
\hline Estadístico Tau & -4.790523 & 0.2871 & No & \multirow{2}{*}{ H1 } \\
\hline Estadístico Z** & -134.5317 & 0.0000 & Sí & \\
\hline
\end{tabular}

Nota: El modelo contiene constante y tendencia. ${ }^{*},{ }^{* *} y^{* * *}$ indican la significación estadística al nivel del 10\%, 5\% y 1\%. Fuente: elaboración propia con datos del BIE del INEGI, con el program Eviews 11. 
Como se puede observar en la Tabla 4, el nivel de significancia del estadísitco "Z" es significativo al 1\%, mientras que el nivel de significancia del estadístiico Tau está por encima de los parámetros (1\%, 5\% y $10 \%)$; a pesar de que Tau no es significativo al $10 \%$, su probabilidad no es alarmante, es decir, no es muy alta. No obstante, el hecho de que alguno de los indicadores estadísticos fuera significativo, hace que la hipótesis nula (Ho) se rechace, denotandose que las variables están cointegradas, y existe relación a largo plazo.

El emplear modelos de regresión de series de tiempo, éste puede presentar cambios estructurales en la relación entre la variable dependiente y las explicativas; es decir, que los valores no permanecen constantes a lo largo del periodo (Gujarati y Porter, 2010; Woodridge, 2010). Los cambios estruturales se deben a factores o sucesos exógenos como cambios en la política, crisis finanieras o económicas, embargos comerciales, entre otras cosas. Para poder observar la existencia de cambios estructurales se emplea la prueba de Chow.

Tabla 5. Prueba de Chow

\begin{tabular}{|c|c|c|c|}
\hline \multicolumn{4}{|c|}{ Ho: Si los valores no son significativos no hay cambio estructural } \\
\hline \multicolumn{4}{|c|}{ H1: Si los valores son significativos hay cambio estructural } \\
\hline Periodo & F-Statistic & Prob F & Prob $\mathrm{X}^{\wedge} 2$ \\
\hline 2008/Q1*** & 2.536874 & 0.0263 & 0.0138 \\
\hline 2008/Q2** & 1.919086 & 0.0871 & 0.0550 \\
\hline 2008/Q3** & 1.946966 & 0.0826 & 0.0517 \\
\hline 2008/Q4* & 1.777745 & 0.1135 & 0.0747 \\
\hline
\end{tabular}

Nota: El modelo contiene constante y tendencia. ${ }^{*},{ }^{* *} y^{* * *}$ indican la significación estadística al nivel del 10\%, 5\% y 1\%.Fuente: elaboración propia con datos del BIE del INEGI, con el program Eviews 11.

Como se observa en la Tabla 5, los resultados de la prueba Chow arrojaron la existencia de un cambio en el año 2008, siendo más fuerte en el primer trimestre (2008/Q1), con un nivel de significancia del 1\%. No obstante, la prueba Chow va acompañada de los gráficos del test Cusum y Cusum Square (veáse Anexo 3), las cuales demarcan un ligero cambio estructural para el año 2008, pues los valores Cusum y Cusum Square salen de los límites. Lo anterior da sustento a la variable dicotómica que implica la existencia de cmabio estructural y, por lo tanto, un posible cambio en el comportamiento del Crédito Bancario otorgado al Consumo (lnCCONS) y el otorgado al Sector Industrial (lnCIND).

Ante los resultados de las pruebas, el siguiente paso es estimar los coeficientes para conocer las relaciones y efectos a largo plazo, de acuerdo a la Ecuación (6). La Tabla 6 presenta los resultados: 
Tabla 6. Estimación a Largo Plazo

\begin{tabular}{|c|c|c|c|c|c|c|c|c|c|c|}
\hline \multicolumn{10}{|c|}{ Coeficientes Estimados a Largo Plazo } \\
\hline $\begin{array}{c}\text { Variable } \\
\begin{array}{c}\text { Dependie } \\
\text { nte }\end{array}\end{array}$ & $\begin{array}{c}\text { Constan } \\
\text { te }\end{array}$ & InCINDt & $\begin{array}{c}\text { InCCON } \\
\text { St }\end{array}$ & $\begin{array}{c}\text { InIMP } \\
\text { BKt }\end{array}$ & $\begin{array}{c}\operatorname{lnEXPO} \\
\mathrm{t}\end{array}$ & $\mathrm{t}$ & BA2008 & $\begin{array}{c}\text { BA2008 } \\
\text { *InCIND }\end{array}$ & $\begin{array}{c}\text { BA2008 } \\
\text { *InCCO } \\
\text { NS }\end{array}$ & AR(1) \\
\hline \multirow{2}{*}{$\operatorname{lnPIB}$} & 8.708 & $\begin{array}{c}0.105 \\
(* *)\end{array}$ & $\begin{array}{c}0.041 \\
(* *)\end{array}$ & 0.017 & $\begin{array}{c}0.405 \\
(* *)\end{array}$ & 0.002 & $\begin{array}{c}3.361 \\
(* *)\end{array}$ & $\begin{array}{c}-0.273 \\
(* *)\end{array}$ & 0.032 & 0.705 \\
\cline { 2 - 11 } & & {$[0.004]$} & {$[0.032]$} & {$[0.425$} & {$[0.000]$} & {$[0.184]$} & {$[0.016]$} & {$[0.013]$} & {$[0.582]$} & \\
\hline
\end{tabular}

Nota: Esta tabla resume los resultados de las estimaciones de las relaciones a largo plazo. Las cifras entre paréntesis son P-Valores. ${ }^{* * *},{ }^{* *} y^{*}$ indican la significancia estadística en el nivel del 1\%, 5\% y 10\%, respectivamente.

Fuente: elaboración propia con datos del BIE del INEGI, con el program Eviews 11.

Como se observa en la Tabla 6, la variable crédito bancario otorgado al sector industrial (lnCIND), Crédito Bancario otorgado al Consumo (lnCCONS), la tendencia ( $\mathrm{t}$ ) y la dicotómica que explica el cambio estructural en el 2008 (BA2008) son significativas al 5\% y 1\%. Asimsimo, los coeficientes tienen los signos esperados. No obstante, los efectos del crédito bancario otorgado al consumo (lnCCONS) después de la crisis financiera del 2008, no es significativa; asimismo, con la variable dicotómica significativa, ayuda a percibir la existencia de un punto de coyuntura antes y después de dicha crisis, sobre los efectos generados por el crédito bancario al consumo y a la industria en el crecimiento económico de México.

Los efectos a largo plazo del crédito bancario otorgado a la industria sobre el PIB mexicano es positivo, donde la elasticidad señala que por cada punto porcentual que incremente el crédito bancario otorgado a la industria (InCIND), el PIB aumenta en $0.10 \%$; por otra parte, el crédito bancario destinado al consumo (lnCCONS) también tiene efectos positivos sobre la economía en el largo plazo, pues por cada punto porcentual de incremento, genera un aumento del PIB en 0.04\%.

Por otra parte, la variable dicotómica BA2008 nos indica la existencia de un cambio en los efectos de las variables lncind y lnccons sobre el crecimiento económico, después del 2008, año en el cual detonó una crisis financiera a nivel mundial; entonces, posterior a dicho año, el crédito bancario destinado a la industrial (BA2008*InCIND) tiene efectos negativos sobre el crecimiento económico por cada punto porcentual de incremento en créditos dirigidos a la industria, el PIB disminuye en $0.27 \%$-, lo cual tiene sentido, pues las empresas no desean invertir en tiempos de crisis; además, la mayor parte de la inversión hecha por las empresas, es a través del créditos con proveedores - de acuerdo con datos de la encuesta coyuntural del mercado crediticio de Banxico, el 79\%, en promedio, de las empresas se financiaron con proveedores, mientras un 34\% con instituciones bancarias, veáse en Anexo 4 -. Por otra parte, el crédito bancario al consumo (BA2008*InCCONS) no es estadísticamente significativo, no obstante, sus efectos sobre el PIB son positivos, pues si aumenta un punto porcentual, la economía mejora en $0.03 \%$.

Lo anterior hace que el modelo propuesto en el presente documento sean viable para poder medir los efectos del crédito bancario, tanto el otorgado al consumo como a la industria, sobre el crecimiento económico del México. En ese sentido, se pueden responder las preguntas que se hacen en la introducción, constatando con las ideas de Levine (1998), Bagehot (1873), Schumpeter (1912), McKinnon (1973), Shaw (1973), Greenwood y Jovanovic (1990); Bencivenga y Smith (1991), King y Levine (1993), Bencivenga et al. (1995), Gurley y Shaw (1955), Khan y Senhadji (2003), Geršl y 
Seidler (2010), Zafar et al. (2012), Fieldhouse, Mertens y Ravn (2018), Guerrieri y Lorenzoni (2017), Agarwal, Chomsisengphet, Mahoney y Stroebel (2017), Sreerama, Sailaja y Mullugeta (2012) y Torre y Flores (2020); las cuales se responden en el siguiente apartado.

\section{Conclusiones y discusión}

En este documento, se han examinado la relación que existe en el crédito bancario - el cual está representado por el crédito otorgado a la industria y el crédito otorgado al consumo -, con el crecimiento económico de México - representado por el PIB -, en el contexto de un modelo autoregresivo con la aplicación de una variable dicotómica para encontrar coyuntura en los efectos de las variables explicativas. Las estimaciones de la ecuación propuesta - PIB - a largo plazo se obtuvieron empleando el enfoque de pruebas de límites para cointegración implementando datos trimestrales para un periodo de 24 años, comprendido desde 1994 hasta 2017.

Los resultados de las pruebas de cointegración arrojan claramente la existencia de un equilibrio a largo plazo entre las variables explicativas y la variable dependiente. La regresión arrojó los signos esperados para los coeficientes. Por otra parte, los coeficientes resultaron estadísticamente significativos, tomando en cuenta el 1\%, 5\% y $10 \%$.

En ese sentido, a pesar de haber una penetración bancaria baja y, por ende, un constreñimiento de crédito en México, el crédito bancario otorgado a la industria y al consumo tienen una relación positiva con el crecimiento económico a largo plazo, es decir, los créditos destinados a esos rubros provocan una mejora de la economía. No obstante, el comportamiento del crédito bancario otorgado a la industria es distinto en periodos poscrisis, momento en el cual se aplican políticas económicas contractivas, para el caso de México, éste genera efectos negativos para el PIB; este hallazgo genera una oportunidad de investigación futura para encontrar las causas del por qué el crédito bancario a la industria genera efectos negativos sobre el PIB entre 2010 y 2017, cuando a partir del 2010 la inversión en México comienza a recuperarse, hay un cojunto de elementos a estudiar como la utilidad del mismo crédito por las empresas, el tamaño de las empresas, la penetracion bancaria, el acceso al credito bancario en el país, entre otras. En el caso crédito bancario destinado al consumo, en periodos poscrisis, deja ser significativo para el crecimiento de la economía mexicana.

De acuerdo con lo anterior, se debe pensar en incrementar de manera regulada estas herramientas para ayudar a mejorar las condiciones de la industria y, por ende, de la economía de México; como implementar requisitos de acceso al crédito bancario más nobles y adhoc, según el rubro económico, ya sea por sector o por tamaño de la empresa.

En cuanto a las limitaciones de esta investigación, una de ellas radica en los datos de las variables seleccionadas, los cuales no están homologados en cuanto el formato de periodos (trimestrales, mensuales, por ejemplo); otra, en el caso de los montos crediticios se dejó de actualizar por parte de INEGI, dificultando poder traer estudio a un periodo más reciente, mientras que las cifras de Banxico y la CNBV no embonan con los arrojados por el BIE del INEGI. Otra limitante se encuentra en los años base de los datos de cada variable, los cuales se homologaron para evitar desfases al correrlos en los modelos econométricos; también, la información del económica de 
México se encuentra agregada, por lo cual limita la posibilidad de llevar a cabo estudios por entidad federativa y/o municipio.

Asimismo, el modelo, por su condición, resultó tener problema de endogeneidad (veáse Anexo 5), no obstante, se pensó en resolverlo con variables instrumentales por medio de regresión bietápica, lo cual no se logró, debido a que la información de numéros de créditos bancarios, otorgados a la industria y al consumo, comienza en el 2008 y son anuales (la encuesta coyuntural de la CNBV). No obstante, el presente estudio marca la pauta para futuras investigación sobre los efectos de crédito bancario en diversos rubros de la economía, o sobre la probabilidad de acceso al crédito bancario por una empresa del sector industrial o, más específico, empresas manufactureras o MIPYMES, los cuales se pueden tratar con modelos LOGIT, PROBIT o TOBIT, de acuerdo con el abordaje de la investigación.

\section{Referencias}

[1] Agarwal, S., Chomsisengphet, S., Mahoney, N., \& Stroebel, J. (2018). "Do Banks Pass Through Credit Expansions To Consumers Who Want To Borrow?" The Quarterly Journal of Economics, vol. 133(1), February, p. 129-190. Recuperado de https://doi.org/10.3386/w21567

[2] Akosah, N. (2013). "Dynamics of Inflation and Financial Development: Empirical Evidence from Ghana," Journal of Economics and Sustainable Development, vol. 4(15), p. 20-37. ISSN: 2225-0522 (online)

[3] Arcand, J., Berkes, E. y Panizza, U. (2015). “Too much finance?” Journal of Economic Growth, vol. 20(2), June, p. 105-148. ISSN: 1573-7020 (online)

[4] Arestis, P., Demetriades, P. \& Luintel, K. (2001). "Financial Development and Economic Growth: The Role of Stock Markets," Journal of Money, Credit, and Banking, vol. 33(1), February, p. 16-41. Recuperado de https://doi.org/10.2307/2673870

[5] Armeanu, D., Pascal, C., Poanta, D. \& Doia, C. (2015). "The credit impact on the economic growth," Theoretical and Applied Economics, vol. 22(1), p.5-14. ISSN: 1844-0029 (online)

[6] Bagehot, W. (1873). "Lombard Street: A description of the money market," The North America Review, vol.119(245), October, p. 331-358. Recuperado de https://doi.org/10.1017/CB09781139093620

[7] Baron, M., y Xiong, W. (2017). "Credit expansion and neglected crash risk," The Quaterly Journal, vol. 132(2), May, p. 713-764. Recuperado de https://doi.org/10.3386/w22695

[8] Barriga, G., González, M., Torres, Y., Zurita, E. \& Pinilla, D. (2018). "Desarrollo financiero y crecimiento económico en el Ecuador: 2000-2017”. Revista Espacios, Vol. 39(37), p. 25-34. ISSN: 07981015.

[9] Bencivenga, V., \& Smith, B. (1991). "Financial Intermediation and Endogenous Growth," Review of Economic Studies, vol. 58(2), April, p. 195-209. Recuperado de https://doi.org/10.2307/2297964

[10] Bencivenga, V., Smith, B., \& Starr, R. (1995). "Transactions costs, technological choice, and endogenous growth," Journal of Economic Theory, vol. 67, p. 153-177. Recuperado de https://doi.org/10.1006/jeth.1995.1069

[11] Bernard, A., \& Jensen, B. (1999). Exporting and productivity. Cambridge: National Bureau of Economic Research. Recuperado de https://doi.org/10.3386/w7135

[12] Bhide, A. (1993). "The hidden costs of stock market liquidity," Journal of financial economics, vol. 34(1), August, p. 31-51. Recuperado de https://doi.org/10.1016/0304-405x(93)90039-e

[13] Cecchetti, G. y Kharroubi, E. (2012). "Reassessing the Impact of Finance on Growth," BIS Working Paper, No.381, July, p. 1-14. ISSN 1682-7678 (online)

[14] Cheng, I., Hong, H. y Scheinkman, J. (2015). "Yesterday's Heroes: Compensation and Creative RiskTaking," Journal of Finance, vol. 70(2), April, p. 839-879. Recuperado de https://doi.org/10.3386/w16176 
REMEF (The Mexican Journal of Economics and Finance)

Los efectos del crédito bancario otorgado a la industria y al consumo en el crecimiento económico: evidencia de México, 1994-2017

[15] Clavellina, J. (2013). "Crédito bancario y crecimiento económico en México". Economía Informa, Vol. 378, enero-febrero, p. 14-36. Recuperado de https://doi.org/10.1016/S0185-0849(13)71306-9

[16] Cruz, M. \& Lapa, J. (2012). "Crisis y recuperación económica: el papel de la política fiscal," Revista Problemas del Desarrollo, Vol. 168(43), enero-marzo, p. 95-115. Recuperado de https://doi.org/10.22201/iiec.20078951e.2012.168.28639

[17] Culp, C., Nozawa, Y., \& Veronesi, P. (2018). “Option-Based Credit Spreads," American Economic Review, vol. 108(2), February, p. 454-488. Recuperado de https://doi.org/10.3386/w20776

[18] Fieldhouse, A., Mertens, K., \& Ravn, M. (2018). "The Macroeconomic effects of Government Asset Purchases: Evidence from Postwar US Housinf Credit Policy," The Quarterly Journal of Economics, vol. 133(3), August, p.1503-1560. Recuperado de https://doi.org/10.3386/w23154

[19] García, M., \& Han, F. (2015). "Credit Expansion in Emerging Markets: Propeller of Growth?" IMF Working Paper, No. 212, September, p. 1-14. Recuperado de https://doi.org/10.5089/9781513581927.001

[20] Geršl, A. \& Seidler, J. (2010). "Excessive credit growth as an indicator of financial (in)stability and its use in macroprudential policy," Czech National Bank. Retraído 28 febrero 2019 de Czech National Bank Web: $\quad$ http://www.cnb.cz/en/financial_stability/fs_reports/fsr_2010-2011/fsr_20102011_article_2.pdf

[21] González, J., Martínez, J. y Rodríguez, F. (2009). "La crisis financiera y económica del 2008. Origen y consecuencias en los Estados Unidos y México”. El Cotidiano, No. 157, septiembre-octubre, p. 17-27. ISSN: 0186-1840

[22] Greenwood, R. y Hanson, S. (2013). "Issues Quality and Corporate Bond Returns," Review of Financial Studies, vol. 26(6), June, p. 1483-1525. Recuperado de https://doi.org/10.1093/rfs/hht016

[23] Greenwood, J., \& Jovanovic, B. (1990). "Financial Development, Growth, and the Distribution of Income," Journal of Political Economy, vol. 98(5), October, p. 1076-1107. Recuperado de https://doi.org/10.3386/w3189

[24] Guerrieri, V., \& Lorenzoni, G. (2017). "Credit Crises, Precautionary Savings, and the Liquidity Trap," The Quarterly Journal of Economics, vol. 132(3), August, p. 1427-1467. Recuperado de https://doi.org/10.3386/w17583

[25] Gurley, J., \& Shaw, E. (1955) "Financial Aspects of Economic Development," The American Economic Review, Vol. 45(4), September, p. 515-538. Recuperado de https://www.jstor.org/stable/1811632

[26] Gujarati, D. \& Porter, D. (2010). Econometría (Quinta Ed.). McGraw-Hill: México. ISBN: 978-607-150294-0

[27] Hassan, K., Sánchez, B., y Yu, J. (2011). "Financial development and economic growth: New evidence from panel data," The Quarterly Review of Economics and Finance, Vol. 51, September, p. 88-104. Recuperado de https://doi.org/10.2139/ssrn.985889

[28] Huang, H. y Lin, S. (2009). "Non-Linear finance-growth nexus: a threshold with instrumental variable approach," Economics of Transition, Vol. 17(3), February, p. 439-466. Recuperado de https://doi.org/10.1111/j.1468-0351.2009.00360.x

[29] Kärnä, A. (2019). "Trade Credit Use and Bank Loan Accers: An Agency Theory Perspective" German Economic Review. Recuperado de https://doi.org/10.1515/ger-2019-0023

[30] Khan, S.M. and Senhadji, A.S. (2003), "Financial Development and Economic Growth: A review and new evidence," Journal of African Economies, vol. 12(2), September, p. 89-110. Recuperado de https://doi.org/10.1093/jae/12.suppl_2.ii89

[31] King, R. y Levine, R. (1993). "Finance and Growth: Schumpeter Might be Right," The Quarterly Journal of Economics, vol. 108(3), August, p. 717-737. Recuperado de https://doi.org/10.2307/2118406

[32] Korkmaz, S. (2015). "Impact of Bank Credits on Economic Growth and Inflation," Journal of Applied Finance \& Banking, vol. 5(1), January, p. 59-69. ISSN: 1792-6599 (online)

[33] Krinichansky, K. \& Sergi, B. (2019). "Financial Development and Economíc Growth in Russia" Modeling Economic Growth in Contemporary Russia, Emerald Publishing Limited, pp. 1-28. Recuperado de https://doi.org/10.1108/978-1-78973-265-820191001 
[34] Landa, H. (2019). "Restricción financiera y crecimiento económico en México". Investigación Económica, Vol. 78(309), p. 27-57. https://doi.org/10.22201/fe.01851667p.2019.309.70118

[35] Law, S. y Singh, N. (2013). "Does too much finance harm economic growth?" Journal of Banking \& Finance, vol. 41, April, p. 36-44. Recuperado de https://doi.org/10.2139/ssrn.3039190

[36] Levine, R. (1991). "Stock Markets, Growth, and Tax Policy". Journal of Finance, vol. 46(4), September, p. 1445-1465. Recuperado de ttps://doi.org/10.1111/j.1540-6261.1991.tb04625.x

[37] --- (1997). "Financial development and economic growth: Views and agenda," Journal of Economic Literature, vol. 35(2), June, p. 688-726. Recuperado de https://doi.org/10.1596/1813-94501678

[38] --- (1998). "The Legal Environment, Banks, and Long-Run Economic Growth," Journal of Money, Credit, and Banking, vol. 30(3), August, p. 596-613. Recuperado de https://doi.org/10.2307/2601259

[39] León, J. \& Alvarado, C. (2015). "México: estabilidad de precios y limitaciones del canal de crédito bancario". Problemas del Desarrollo, Vol. 46(181), abril-junio, p. 75-100. Recuperado de https://doi.org/10.1016/j.rpd.2015.03.002

[40] Lucas, R. (1988). "On the mechanics of economic development," Journal of Monetary Economics, vol. 22, February, p. 3-42 Recuperado de https://doi.org/10.1016/0304-3932(88)90168-7

[41] Mah, J. \& Yoon, S. (2020). "The Effects of Grants and Loans on Economic Growth in Sub-Sahara Africa: Considering Different Types of Income Level" The Journal of International Trade \& Economic, Vol. 29(5), p. 604-618. Recuperado de https://doi.org/10.1080/09638199.2019.1708962

[42] Martín, A., \& Ventura, J. (2012). "Economic Growth with Bubbles," American Economic Review, vol. 102(6), October, p. 3033-3058. Recuperado de https://doi.org/10.3386/w15870

[43] Masuduzzaman, M., Parveen, F., Islam, S. \& Dipty, S. (2019). "Role of Bank Loans for Increasing the Productivity of Small and Medium Sized Enterprises (SMEs) in Bangladesh" Australian Academy of Accounting and Finance Review, 5(2), p. 85-93. ISSN (Online) 2205-6688

[44] McKinnon, R. (1973). Money and capital in economic development.Washington, DC: Brookings Institution. Recuperado de https://doi.org/10.1016/0305-750x(74)90098-9

[45] Miao, J., \& Wang, P. (2017). "Asset Bubbles and Credit Constraints," American Economic Review, vol. 108(9), September, p. 2590-262. Recuperado de https://doi.org/10.1257/aer.20160782

[46] Montoya, J. (2016). "El Desarrollo Financiero y Crecimiento Económico". Revista Electrónica de Investigación en Ciencias Económicas, Vol. 4(7), enero-junio, p. 325-349. Recuperado de https://doi.org/10.5377/reice.v4i7.2837

[47] Obstfeld, M. (1994). "Evaluating risky consumption paths: The role of intertemporal substitutability," European Economic Review, vol. 38(7), August, p. 1471-1486. Recuperado de https://doi.org/10.3386/t0120

[48] OCDE (2017). Estudios Económicos de la OCDE: México. Recuperado de https://doi.org/10.1787/9789264269040-2-es

[49] Ortiz, A. (2009). "Impacto de la crisis económica global en la economía mexicana, 2008-2009 y perspectivas en el corto plazo," Dimensión Económica, septiembre-diciembre, vol. 1(1), p. 1-6. ISSN: $2007-1892$

[50] Romero, E., \& Minto, G. (2010). “Crisis y recuperación de la economía mexicana,” Dimensión Económica, vol. 1(3), mayo-agosto, p. 67-79. Recuperado de http://revistas.unam.mx/index.php/rde/article/view/21551

[51] Schularick, M. y Taylor, A. (2012). "Credit Booms Gone Bust: Monetary Policy, Levarage Cycles and Financial Crises, 1870-2008," American Economic Review, vol. 102(2), p. 1029-106. Recuperado de https://doi.org/10.3386/w15512

[52] Schumpeter, J. (1912). The theory of economic development. Cambridge, MA: Harvard University Press. Recuperado de https://doi.org/10.1007/0-306-48082-4_3

[53] Shaw, E. (1973). Financial deepening in economic development. New York: Oxford University Press. Recuperado de https://doi.org/10.2307/2230515

[54] Shleifer, A., y Vishny, R. (1986). "Large shareholders and corporate control" Journal of political economy, vol. 94(3), p. 461-488. Recuperado de https://doi.org/10.1086/261385 
REMEF (The Mexican Journal of Economics and Finance)

Los efectos del crédito bancario otorgado a la industria y al consumo en el crecimiento económico: evidencia de México, 1994-2017

[55] Smith, V. (1994). "Economics in the laboratory," Journal of Economic Perspectives, vol. 8(1), p. 113-131. Recuperado de https://doi.org/10.1017/cbo9780511819025.023

[56] Sreerama, K., Sailaja, K. \& Mullugeta, W. (2012). "The Long-Run Impact of Bank Credit on Economic Growth in Ethiopia," European Journal of Business and Management, vol. 4(14), October, p. 20-33. ISSN 2222-2839 (Online)

[57] Támara, L., Eusse, L. \& Castellón, A. (2017). “Desarrollo financiero sobre el crecimiento económico de Colombia y Chile, 1982-2014”. Finanzas y Política Económica, Vol. 9(1), p. 57-67. Recuperado de http://dx.doi.org/10.14718/revfinanzpolitecon.2017.9.1.4.

[58] Tóala, I., Navarro, D. \& Hablich, F. (2018). "Diagnóstico de la prticipación del Sector Bancario Privado como herramienta para el Creciemiento Económico del Ecuador periodo 2015-2017". Revista Científica de Investigación Actualización del Mundo de las Ciencias, Vol. 2(1), p. 1036-1050. Recuperado de https://doi.org/10.26820/reciamuc/2.1.2018.1036-1050

[59] Torre, L. \& Flores, M. (2020). "Crédito Bancario al Sector Privado y Crecimiento Económico en México: Un Análisis con Datos de Panel por Entidad Federativa 2005-2018”. Banco de México, No. 2020-17. Recuperdo de https://www.banxico.org.mx/publicaciones-y-prensa/documentos-de-investigaciondel-banco-de-mexico/\%7B7B135C9F-CC2C-B5D8-A73F-02AE7519E04F\%7D.pdf

[60] Woodridge, J. (2010). Introducción a la econometría: un enfoque moderno (Cuarta Ed.). CENGAGE Learning: México. ISBN-13: 978-607-481-312-8

[61] Zafar, M., Ahmad, N. \& Hussain, Z. (2012). "Impact of Savings and Credit on Economic Growth in Pakistan," Pakistan Journal of Social Sciences, vol. 32(1), p. 39-48. ISSN: 1638-883

[62] Zhang, J., Wang, L. y Wang, S. (2012). "Financial Development and Economic Growth: Recent Evidence from China," Journal of Comparative Economics, vol. 40(3), August, p. 393-412. Recuperado de https://doi.org/10.1016/j.jce.2012.01.001

[63] Zhang, Y., Zhai, L. \& Sun, H. (2019). "Does the Level of Financial Leasing Matter in the Impact of Bank Lending on Economic Growth: Evidence from the Global Market (2006-2016)" Finance Research Letters, Vol. 30, p. 352-359. Recuperado de https://doi.org/10.1016/j.frl.2018.10.020

\section{Biografía}

David Salvador Cisneros Zepeda es Doctor en Ciencias Sociales por la Universidad Autónoma de Sinaloa. Profesor de la Universidad Autónoma de Sinaloa, adscrito a los cursos de Macroeconomía, Estadística y Probabilidad, y Matemáticas. Se puede contactar en la Facultad de Estudios Internacionales y Políticas Públicas, prolongación Josefa Ortiz de Domínguez s/n Polígono Sur, Ciudad Universitaria, Culiacán, Sinaloa. Correo electrónico david.cisneros@uas.edu.mx 
Anexo 1. Crédito otorgado por la Banca Comercial a las actividades productivas en México: 1994-2017.

\begin{tabular}{|c|c|c|c|c|c|c|c|c|c|c|}
\hline Año & \multicolumn{2}{|c|}{ Agropecuario } & \multicolumn{2}{|c|}{ Industria } & \multicolumn{2}{|c|}{ Servicios } & \multicolumn{2}{|c|}{ Crédito a Vivienda } & \multicolumn{2}{|c|}{ Consumo } \\
\hline 1994 & $\$ 477,348.00$ & $7.09 \%$ & $\$ 1,911,936.00$ & $28.41 \%$ & $\$ 2,566,474.80$ & $38.14 \%$ & $\$ 1,212,814.80$ & $18.02 \%$ & $\$ \quad 560,319.60$ & $8.33 \%$ \\
\hline 1995 & $\$ 485,126.00$ & $6.64 \%$ & $\$ 2,062,645.10$ & $28.22 \%$ & $\$ 2,716,677.70$ & $37.17 \%$ & $\$ 1,531,874.40$ & $20.96 \%$ & $\$ \quad 511,946.10$ & $7.01 \%$ \\
\hline 1996 & $\$ 543,697.00$ & $6.35 \%$ & $\$ 2,479,413.60$ & $28.95 \%$ & $\$ 2,673,360.30$ & $31.22 \%$ & $\$ 2,417,553.60$ & $28.23 \%$ & $\$ \quad 450,243.40$ & $5.26 \%$ \\
\hline 1997 & $\$ 565,711.00$ & $6.13 \%$ & $\$ 2,552,005.80$ & $27.64 \%$ & $\$ 2,917,104.10$ & $31.59 \%$ & $\$ 2,821,111.90$ & $30.55 \%$ & $\$ \quad 377,540.30$ & $4.09 \%$ \\
\hline 1998 & $\$ 556,064.00$ & $6.12 \%$ & $\$ 2,671,111.90$ & $29.39 \%$ & $\$ 2,777,877.20$ & $30.57 \%$ & $\$ 2,720,079.10$ & $29.93 \%$ & $\$ \quad 362,722.40$ & $3.99 \%$ \\
\hline 1999 & $\$ 559,134.30$ & $5.93 \%$ & $\$ 2,633,127.30$ & $27.93 \%$ & $\$ 2,812,247.90$ & $29.83 \%$ & $\$ 3,018,908.40$ & $32.03 \%$ & $\$ \quad 403,014.20$ & $4.28 \%$ \\
\hline 2000 & $\$ 452,297.30$ & $5.25 \%$ & $\$ 2,328,931.00$ & $27.01 \%$ & $\$ 2,631,947.20$ & $30.53 \%$ & $\$ 2,759,391.30$ & $32.00 \%$ & $\$ \quad 449,336.40$ & $5.21 \%$ \\
\hline 2001 & $\$ 403,540.50$ & $5.20 \%$ & $\$ 2,116,632.30$ & $27.28 \%$ & $\$ 2,468,189.20$ & $31.81 \%$ & $\$ 2,161,796.30$ & $27.86 \%$ & $\$ \quad 610,171.90$ & $7.86 \%$ \\
\hline 2002 & $\$ 279,498.30$ & $3.94 \%$ & $\$ 1,858,131.60$ & $26.17 \%$ & $\$ 2,202,689.30$ & $31.02 \%$ & $\$ 1,937,113.00$ & $27.28 \%$ & $\$ 823,647.60$ & $11.60 \%$ \\
\hline 2003 & $\$ 238,846.10$ & $3.24 \%$ & $\$ 1,902,432.00$ & $25.83 \%$ & $\$ 2,340,340.80$ & $31.77 \%$ & $\$ 1,733,793.00$ & $23.54 \%$ & \$ $1,151,156.40$ & $15.63 \%$ \\
\hline 2004 & $\$ 245,143.70$ & $3.10 \%$ & $\$ 1,882,024.30$ & $23.80 \%$ & $\$ 2,418,221.50$ & $30.58 \%$ & $\$ 1,636,834.10$ & $20.70 \%$ & $\$ 1,726,405.30$ & $21.83 \%$ \\
\hline 2005 & $\$ 246,245.80$ & $2.64 \%$ & $\$ 2,008,749.50$ & $21.51 \%$ & $\$ 2,670,567 \cdot 10$ & $28.60 \%$ & $\$ 1,801,086.90$ & $19.29 \%$ & $\$ 2,610,170.30$ & $27.96 \%$ \\
\hline 2006 & $\$ 241,019.40$ & $2.03 \%$ & $\$ 2,063,563.00$ & $17.37 \%$ & $\$ 3,072,954.30$ & $25.87 \%$ & $\$ 2,572,584.90$ & $21.66 \%$ & $\$ 3,927,291.10$ & $33.07 \%$ \\
\hline 2007 & $\$ 281,334.20$ & $1.81 \%$ & $\$ 3,018,967.80$ & $19.46 \%$ & $\$ 3,832,200.00$ & $24.70 \%$ & $\$ 3,153,342.60$ & $20.32 \%$ & $\$ 5,230,095.80$ & $33.71 \%$ \\
\hline 2008 & $\$ 353,836.80$ & $1.87 \%$ & $\$ 4,066,997.40$ & $21.54 \%$ & $\$ 4,849,710.30$ & $25.69 \%$ & $\$ 3,677,537.00$ & $19.48 \%$ & $\$ 5,930,913.00$ & $31.42 \%$ \\
\hline 2009 & $\$ 363,032.50$ & $1.86 \%$ & $\$ 4,870,969.70$ & $24.93 \%$ & $\$ 5,129,643.90$ & $26.26 \%$ & $\$ 4,030,139.30$ & $20.63 \%$ & $\$ 5,142,457.20$ & $26.32 \%$ \\
\hline 2010 & $\$ 385,791.20$ & $1.93 \%$ & $\$ 5,121,480.90$ & $25.66 \%$ & $\$ 5,290,679.20$ & $26.51 \%$ & $\$ 4,400,918.80$ & $22.05 \%$ & $\$ 4,760,613.20$ & $23.85 \%$ \\
\hline 2011 & $\$ 523,492.30$ & $2.03 \%$ & $\$ 6,356,212.30$ & $24.69 \%$ & $\$ 6,806,496.80$ & $26.44 \%$ & $\$ 5,283,302.20$ & $20.52 \%$ & $\$ 6,773,969.40$ & $26.31 \%$ \\
\hline 2012 & $\$ 523,492.30$ & $2.03 \%$ & $\$ 6,356,212.30$ & $24.69 \%$ & $\$ 6,806,496.80$ & $26.44 \%$ & $\$ 5,283,302.20$ & $20.52 \%$ & $\$ 6,773,969.40$ & $26.31 \%$ \\
\hline 2013 & $\$ 604,728.00$ & $2.12 \%$ & $\$ 6,881,843.70$ & $24.15 \%$ & $\$ 7,488,523.60$ & $26.28 \%$ & $\$ 5,694,757.40$ & $19.99 \%$ & $\$ 7,822,105.30$ & $27.45 \%$ \\
\hline 2014 & $\$ 637,594.20$ & $2.07 \%$ & $\$ 7,186,019.10$ & $23.32 \%$ & $\$ 8,395,440.00$ & $27.24 \%$ & $\$ 6,160,521.50$ & $19.99 \%$ & $\$ 8,439,350.50$ & $27.38 \%$ \\
\hline 2015 & $\$ 699,006.70$ & $2.05 \%$ & $\$ 8,195,796.50$ & $23.98 \%$ & $\$ 9,439,576.00$ & $27.62 \%$ & $\$ 6,817,997.40$ & $19.95 \%$ & $\$ 9,027,321.70$ & $26.41 \%$ \\
\hline 2016 & $\$ 827,690.20$ & $2.12 \%$ & $\$ 9,320,742.80$ & $23.82 \%$ & $\$ 11,191,554.90$ & $28.60 \%$ & $\$ 7,646,553.80$ & $19.54 \%$ & $\$ 10,139,734.40$ & $25.92 \%$ \\
\hline 2017 & $\$ 913,037.10$ & $2.09 \%$ & $\$ 10,250,198.20$ & $23.43 \%$ & $\$ 13,231,942.50$ & $30.24 \%$ & $\$ 8,465,017.20$ & $19.35 \%$ & $\$ 10,894,181.50$ & $24.90 \%$ \\
\hline
\end{tabular}

Fuete: elaboración propia con datos del INEGI (inegi.org.mx). Nota: año base 2013.

Anexo 2. Crédito otorgado por la Banca de Desarollo a las actividades productivas en México: 1994-2017.

\begin{tabular}{|c|c|c|c|c|c|c|c|c|c|c|c|c|c|c|c|}
\hline $\begin{array}{l}\text { Año } \\
1994 \\
\end{array}$ & $\$$ & $139,104.00$ & $24.28 \%$ & $\$$ & $204,060.00$ & $34.25 \%$ & $\$$ & $185,835.60$ & $32.43 \%$ & $\$$ & $24,310.80$ & $4.24 \%$ & $\$$ & $19,706.40$ & $3.44 \%$ \\
\hline 1995 & $\$$ & $161,169.00$ & $23.97 \%$ & $\$$ & $257,895.00$ & $35.17 \%$ & $\$$ & $203,376.00$ & $30.24 \%$ & $\$$ & $28,192.40$ & $4.19 \%$ & $\$$ & $21,866.40$ & $3.25 \%$ \\
\hline 1996 & $\$$ & $207,862.00$ & $26.02 \%$ & $\$$ & $351,365.00$ & $35.84 \%$ & $\$$ & $178,653.20$ & $22.36 \%$ & $\$$ & $34,910.00$ & $4.37 \%$ & $\$$ & $26,054.00$ & $3.26 \%$ \\
\hline 1997 & $\$$ & $226,075.00$ & $28.28 \%$ & $\$$ & $330,953.30$ & $34.03 \%$ & $\$$ & $166,530.50$ & $20.83 \%$ & $\$$ & $42,210.10$ & $5.28 \%$ & $\$$ & $33,604.10$ & $4.20 \%$ \\
\hline 2000 & $\$$ & $165,536.00$ & $22.56 \%$ & $\$$ & $386,993.30$ & $38.34 \%$ & $\$$ & $101,196.60$ & $13.79 \%$ & $\$$ & $34,967.30$ & $4.77 \%$ & $\$$ & $45,063.20$ & $6.14 \%$ \\
\hline 2001 & $\$$ & $184,949.40$ & $22.30 \%$ & $\$$ & $424,988.60$ & $38.33 \%$ & $\$$ & $107,880.50$ & $13.01 \%$ & $\$$ & $36,864.80$ & $4.45 \%$ & $\$$ & $74,593.70$ & $9.00 \%$ \\
\hline 2002 & $\$$ & $197,087.30$ & $21.03 \%$ & $\$$ & $472,949.80$ & $38.56 \%$ & $\$$ & $143,663.50$ & $15.33 \%$ & $\$$ & $41,840.80$ & $4.46 \%$ & $\$$ & $81,758.40$ & $8.72 \%$ \\
\hline
\end{tabular}


REMEF (The Mexican Journal of Economics and Finance)

Los efectos del crédito bancario otorgado a la industria y al consumo en el crecimiento económico:

evidencia de México, 1994-2017

\begin{tabular}{|c|c|c|c|c|c|c|c|c|c|c|c|c|c|c|c|}
\hline 2004 & $\$$ & $132,206.60$ & $14.77 \%$ & $\$$ & $468,411.00$ & $41.03 \%$ & $\$$ & $189,297.10$ & $21.14 \%$ & $\$$ & $36,281.30$ & $4.05 \%$ & $\$$ & $69,147.70$ & $7.72 \%$ \\
\hline 2006 & $\$$ & $10,180.90$ & $1.71 \%$ & $\$$ & $297,340.40$ & $42.56 \%$ & $\$$ & $156,005.00$ & $26.14 \%$ & $\$$ & $46,917.20$ & $7.86 \%$ & $\$$ & $86,433.30$ & $14.48 \%$ \\
\hline 2007 & $\$$ & $4,523.70$ & $0.78 \%$ & $\$$ & $280,610.10$ & $42.00 \%$ & $\$$ & $149,671.40$ & $25.69 \%$ & $\$$ & $51,222.00$ & $8.79 \%$ & $\$$ & $96,627.30$ & $16.58 \%$ \\
\hline 2008 & $\$$ & $4,063.90$ & $0.63 \%$ & $\$$ & $301,255.70$ & $40.96 \%$ & $\$$ & $169,466.30$ & $26.11 \%$ & $\$$ & $64,478.40$ & $9.93 \%$ & $\$$ & $109,747.90$ & $16.91 \%$ \\
\hline 2011 & $\$$ & $6,241.10$ & $0.34 \%$ & $\$$ & $1,188,401.60$ & $45.19 \%$ & $\$$ & $359,360.90$ & $19.35 \%$ & $\$$ & $123,300.90$ & $6.64 \%$ & $\$$ & $180,226.30$ & $9.70 \%$ \\
\hline 2012 & $\$$ & $6,241.10$ & $0.34 \%$ & $\$$ & $1,188,401.60$ & $45.19 \%$ & $\$$ & $359,360.90$ & $19.35 \%$ & $\$$ & $123,300.90$ & $6.64 \%$ & $\$$ & $180,226.30$ & $9.70 \%$ \\
\hline 2013 & $\$$ & $16,026.10$ & $0.73 \%$ & $\$$ & $1,397,065.40$ & $45.33 \%$ & $\$$ & $466,884.40$ & $21.15 \%$ & $\$$ & $135,960.30$ & $6.16 \%$ & $\$$ & $191,690.90$ & $8.68 \%$ \\
\hline 2014 & $\$$ & $29,378.50$ & $1.06 \%$ & $\$$ & $1,673,178.70$ & $45.72 \%$ & $\$$ & $700,953.80$ & $25.22 \%$ & $\Phi$ & $141,893.50$ & $5.10 \%$ & $\$$ & $234,427.60$ & $8.43 \%$ \\
\hline 2017 & $\$$ & $26,328.70$ & $0.57 \%$ & $\$$ & $2,420,915.60$ & $46.66 \%$ & $\$$ & $1,592,760.60$ & $34.19 \%$ & $\$$ & $160,394.20$ & $3.44 \%$ & $\$$ & $457,968.00$ & $9.83 \%$ \\
\hline
\end{tabular}

Fuete: elaboración propia con datos del INEGI (inegi.org.mx). Nota: año base 2013.

\section{Anexo 3. Pruebas Cusum y Cusum of Square para Cambio Estructural}

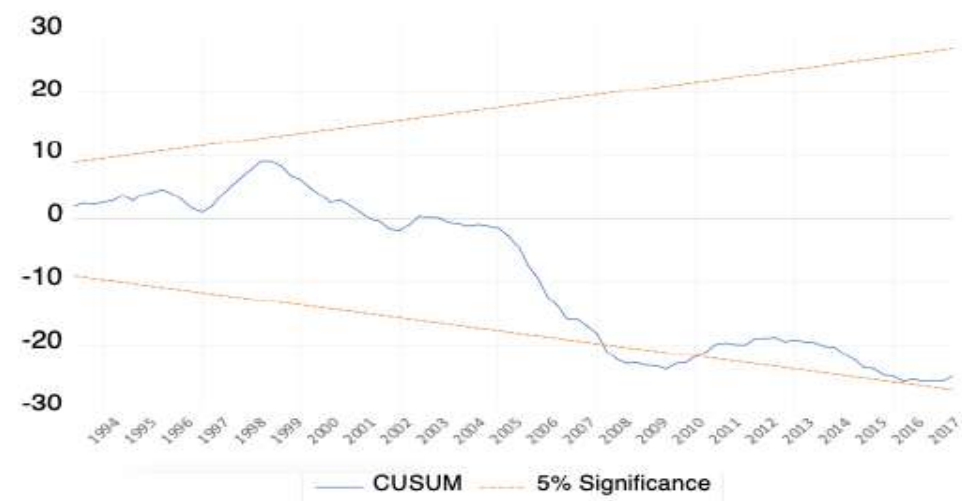

Fuente: elaboración con datos del BIE del INEGI con el programa Eviews 11



Fuente: elaboración con datos del BIE del INEGI con el programa Eviews 11 
Anexo 4. Tipos de crédito obtenidos por las empresas en México: promedios anuales, 2008-2017



Fuente: elaboración propia con base de datos de la Encuesta Coyuntural del Mercado Crediticio de BANXICO (banxico.org).

Anexo 5. Pruebas de Causalidad de Granger
\begin{tabular}{|c|c|c|c|c|c|}
\hline \multicolumn{2}{|c|}{ Relación Causal } & Rezago & $\mathbf{X}^{\wedge} \mathbf{2}$ & $\boldsymbol{p}$-value \\
\hline PIB (lnpib) & $\Rightarrow$ & Crédito al Consumo (lnccons) & 1 & 36.45899 & 0.0000 \\
\hline Crédito al Consumo (lnccons) & $\nRightarrow$ & PIB (lnpib) & 1 & 0.325623 & 0.5682 \\
\hline PIB (lnpib) & $\Rightarrow$ & Crédito al Consumo (lnccons) & 2 & 14.22076 & 0.0008 \\
\hline Crédito al Consumo (lnccons) & $\nRightarrow$ & PIB (lnpib) & 2 & 0.667892 & 0.7161 \\
\hline PIB (lnpib) & $\Rightarrow$ & Crédito a la Industria (lncind) & 1 & 29.81588 & 0.0000 \\
\hline Crédito a la Industria (lncind) & $\nRightarrow$ & PIB (lnpib) & 1 & 0.004586 & 0.9460 \\
\hline PIB (lnpib) & $\Rightarrow$ & Crédito a la Industria (lncind) & 2 & 9.066918 & 0.0107 \\
\hline Crédito a la Industria (lncind) & $\Rightarrow$ & PIB (lnpib) & 2 & 1.024326 & 0.5992 \\
\hline
\end{tabular}

Nota: el símbolo ? denota "no causalidad", y el símbos ? denota "causalidad". Los símbolos *, ** ${ }^{* * *}$ se refieren al nivel significanci en 10\%, 5\% y 1\%, respectivamente.

Fuente: elaboración propia con datos del BIE del INEGI, con el program Eviews 11. 